\title{
La movilización etnopolítica afromexicana de la Costa Chica de Guerrero y Oaxaca en el marco de las luchas afrodescendientes
} de América Latina en $2017^{1}$ The Afro-Mexican Ethnopolitical Mobilization of the Costa Chica of Guerrero and Oaxaca within the Framework of the Afro-descendant Struggles of Latin America in 2017

América Nicte-Ha López Chávez Universidad Autónoma de Madrid ame.lopez24@gmail.com

\section{RESUMEN}

Se recupera el caso de la movilización etnopolítica afromexicana de la Costa Chica de Guerrero y Oaxaca desde una mirada global. Se hace un breve análisis del contexto general de las luchas afrodescendientes en América Latina, para después situarse en el contexto particular de la movilización etnopolítica afromexicana. El debate se enfoca en la demanda y el reconocimiento de derechos por medio de políticas multiculturales y el ejercicio, efectivo o no, de éstos. El objetivo es identificar los principales derechos conquistados (políticas multiculturales) por las luchas afrodescendientes de América Latina, para establecer la posición en la que se inserta la movilización etnopolítica afromexicana en este marco. Se desarrolla en el marco teórico multicultural con fuentes primarias y secundarias, entrevistas, trabajo de campo, y sistematiza los datos obtenidos recurriendo al método comparativo. Los resultados muestran que, si bien la movilización etnopolítica afromexicana es una lucha social relativamente nueva en México, en comparación con el resto de América Latina, su emergencia es tardía y ha logrado conquistar muy pocas políticas multiculturales que les permitan empoderarse e incluirse socialmente.

PALABRAS CLAVE: afrodescendientes, América Latina, México, multiculturalismo

\section{ABSTRACT}

This article recovers the case of the AfroMexican ethnopolitical mobilization of the Costa Chica of Guerrero and Oaxaca from a global perspective. It begins with a brief analysis of the general context of the Afrodescendant struggles in Latin America, and then situates itself in the particular context of the Afro-Mexican ethno-political mobilization. The debate focuses on the demand and recognition of rights through multicultural policies and the exercise, effective or not, of them. The objective is to identify the main conquered rights (multicultural policies) for Afro-descendants in Latin America, and then establish the position in which the Afro-Mexican ethno-political mobilization is inserted in this framework. The article is developed within the multicultural theoretical framework, uses primary and secondary sources, interviews, fieldwork, and systematizes the data using the comparative method. Results show that, although the Afro-Mexican ethno-political mobilization is a relatively new social struggle in Mexico, compared to the rest of Latin America, its emergence is late and has achieved very few multicultural policies that will able them to empower and be socially included.

KEY WORDS: People of African Descent, Latin America, Mexico, Multiculturalism

\footnotetext{
${ }^{1} \mathrm{El}$ artículo forma parte de la investigación para mi tesis doctoral Afrodescendientes en América Latina. Estudio de caso de la movilización etnopolítica afromexicana de la Costa Chica de Guerrero y Oaxaca, México (1997-2016).
} 


\section{INTRODUCCIÓN}

El objetivo del artículo es delinear un marco que reúna los principales derechos conquistados por las luchas afrodescendientes de 18 países latinoamericanos (Argentina, Belice, Bolivia, Brasil, Chile, Colombia, Costa Rica, Ecuador, El Salvador, Guatemala, Honduras, México, Nicaragua, Panamá, Paraguay, Perú, Uruguay y Venezuela) e identificar la posición en la que se inserta la movilización etnopolítica afromexicana en este marco. La hipótesis que se sostiene, es que ésta se posiciona como una de las luchas afrodescendientes en América Latina que emergió tardíamente, tiene interacciones débiles con actores internacionales clave en movimientos afrodescendientes y presenta un avance menor respecto a derechos conquistados. Por tanto, su búsqueda de empoderamiento, justicia e inclusión social está apenas iniciando. El artículo busca aportar, desde la Ciencia Política, un texto que muestre la existencia de una movilización de corte etnopolítico en la Costa Chica de Guerrero y Oaxaca, que busca justicia e inclusión social. Para lograr el objetivo y comprobar la hipótesis sostenida, se utilizaron fuentes secundarias, como material producido por académicos y Organismos Internacionales, y fuentes primarias publicadas como constituciones políticas, leyes, censos y encuestas. La información se sistematizó y organizó recurriendo al método comparativo.

El artículo inicia estableciendo el contexto multicultural en el que emergen los movimientos afrodescendientes en América Latina. Posteriormente, proporciona un breve perfil sociodemográfico y datos estadísticos de los afrodescendientes de la región; después, identifica los principales derechos conquistados, los cuales se estructuran en políticas multiculturales, políticas de acción afirmativa y políticas públicas. En la siguiente sección, se muestra la configuración de las organizaciones afrodescendientes y el papel de las redes nacionales y transnacionales en estos procesos de organización y empoderamiento. Los cambios sociales que mostraron algunas naciones después de que sus Estados implementaron políticas multiculturales, se ejemplifican brevemente con los casos de Brasil, Colombia y Honduras. Finalmente, una vez delineado este marco, se insertan los derechos que ha logrado la movilización etnopolítica afromexicana de la Costa Chica de Guerrero y Oaxaca, con el objetivo de identificar su posicionamiento y avance respecto a las luchas afrodescendientes de América Latina. 


\section{LAS LUCHAS AFRODESCENDIENTES DE AMÉRICA LATINA EN EL MARCO MULTICULTURAL}

Los movimientos sociales que se configuraron y emergieron en las décadas de los sesenta y los setenta del siglo XX en Estados Unidos y Canadá (Kymlicka, 2007), impactaron en la región latinoamericana (Sansone citado por Agudelo, 2010) en las décadas de los setenta y ochenta, primero con la movilización y reivindicación política de los pueblos indígenas y, posteriormente, de las poblaciones afrodescendientes (Agudelo, 2011, 2015). La emergencia de estas luchas provocó que los Estados, en algunas ocasiones presionados por Organismos Internacionales y agencias financieras como el Banco Mundial (López, 2017), implementaran políticas que permitieran su visibilización, reconocimiento jurídico como sujetos culturalmente diferentes con derechos y obligaciones y, por tanto, receptores de políticas para su empoderamiento e integración social, política, económica y cultural (García, 2016; Kymlicka, 2007; Sieder, 2002; Van Cott, 2000a). No existe una definición aceptada de multiculturalismo (Kymlicka, 2007; Lehmann, 2016, Wieviorka, 2014) y cualquier intento por establecer una puede dejar alguna variable fuera. Así pues, para efectos de este artículo, multiculturalismo y políticas multiculturales se refieren a las políticas aplicadas por el Estado en respuesta a las demandas sociales, políticas, económicas y culturales de los movimientos afrodescendientes de América Latina. Aunque existen múltiples categorías para referirse a nuestro sujeto de estudio (negro, costeńo, moreno) y cada una tiene su propio significado, utilizaré afromexicano y afrodescendiente de forma indistinta. La primera, por ser la categoría política elegida por la movilización afromexicana, y la segunda, por ser una categoría aceptada y adoptada internacionalmente por representantes afrodescedientes en la cumbre de Durban (Lao Montes, 2009).

Estos procesos de emergencia suceden al final de la Guerra Fría, en el contexto de un mundo multipolar y globalizado, la introducción del sistema económico neoliberal a la región que, a su vez, configuró un nuevo sistema de gobernanza y constituyó una sociedad civil global que se caracterizó por participar activamente en organismos internacionales, organismos no gubernamentales (ONG) y movimientos sociales transnacionales. El Estado neoliberal no tuvo 
inconveniente en transferir a los nuevos actores sus responsabilidades para cubrir las necesidades ciudadanas básicas, por medio de programas y proyectos de autogestión (Favre y Segato citados en Agudelo y Recondo, 2007). Sin embargo, es importante tener en cuenta los contextos específicos de cada país, pues de ellos dependerá la respuesta del Estado, las posibilidades de conquistar derechos y, por tanto, el grado de posicionamiento de las luchas (Kymlicka, 2007, Lechini, 2008, Agudelo y Recondo, 2007, p. 9).

La emergencia de estas luchas sociales latinoamericanas ha sido organizada por Le Bot (2009) en tres etapas. La primera va de mediados de los sesenta hasta principios de los setenta del siglo XX. Se caracteriza por ser el inicio de las demandas sociales y políticas de los pueblos indígenas al Estado, como la obtención de títulos de la propiedad colectiva de la tierra, la autonomía política y la libre determinación. La segunda se desarrolla de mediados de la década de los setenta hasta 1992, cuando ocurren las movilizaciones contra la celebración del V Centenario del Descubrimiento de América (Buffa y Becerra, 2012; García, 2016; Le Bot, 2009). Además, en este momento, las políticas neoliberales, introducidas en la década de los ochenta fueron cuestionadas por sus efectos negativos en el ámbito social, económico y político de la región (Lao, 2009, 2015). En esta etapa se consolidaron los modos de organización política y las líneas de trabajo, pues es cuando demandan la implementación de políticas multiculturales y los indígenas latinoamericanos se transformaron en "importantes actores sociales y políticos capaces de influir en las ‘agendas políticas` de todos los programas de gobierno latinoamericanos, y [por tanto, estaban] convirtiéndose en objeto de preocupación de diversos sectores empresariales, organismos internacionales y agencias multilaterales" (Bengoa, citado en García, 2016, p. 18). En México, los indígenas se organizaron, por ejemplo, en el Consejo Guerrerense 500 años de Resistencia Indígena y Popular, que después pasó a ser Consejo Guerrerense 500 años de Resistencia Indígena, Negra y Popular, o en el Ejercito Zapatista de Liberación Nacional. Esos grupos denunciaban la falta de servicios básicos como agua y electricidad en sus comunidades, así como la corrupción, la opresión y el abuso de poder del Estado hacia ellos. Por tanto, entre sus demandas se encontraron la autonomía política y la libre determinación. La demanda de la propiedad colectiva de 
la tierra no era tan fuerte como en el resto de América Latina, porque la reforma agraria de 1917 ya estipulaba formas de repartición (EZLN, 1996; Burguete y Mayor, 2003).

La tercera etapa abarca los años de 1992 a 2005 y es clasificada como la de consolidación de los movimientos sociales, pues los pueblos indígenas fueron finalmente reconocidos como actores políticos y sujetos de derecho (Le Bot, 2009) de las políticas multiculturales demandadas en la etapa anterior. La elección de Evo Morales como presidente de Bolivia, en 2005, es un ejemplo del empoderamiento que experimentaron. Si bien estas etapas pertenecen a los procesos de luchas y movimientos indígenas, establecieron las bases y fueron referente de los procesos organizativos de los pueblos negros (Lara, 2014). Por tanto, ordenar las temporalidades de los procesos puede ser útil para situar el momento en el que irrumpen los afrodescendendientes, y en el que sus procesos y luchas se traslapan con las de los indígenas. También muestra que los procesos organizativos de estas movilizaciones sociales tienen un largo recorrido, condicionado por contextos sociales, políticos y económicos, nacionales e internacionales, no son pues, reivindicaciones esporádicas y temporales.

\section{BREVE PERFIL SOCIODEMOGRÁFICO DEL AFRODESCENDIENTE EN AMÉRICA LATINA}

La región de América Latina y el Caribe fue clasificada a inicios del milenio por el Banco Mundial (De Ferranti et al., 2004) como una de las regiones con la peor distribución de ingreso y, por tanto, con más desigualdades en el mundo. Los pueblos indígenas y las poblaciones afrodescendientes resultaron ser las más desfavorecidas por esta mala distribución y desigualdad. De acuerdo con un estudio realizado por la CEPAL, a mediados de la década de los noventa del siglo XX y a mediados de la segunda década del siglo XXI, ambos presentaron los peores indicadores económicos y sociales, así como los niveles de pobreza y desigualdad más altos (CEPAL, 2015; PNUD, 2016; Psacharopoulos y Patrinos, 1994).

De acuerdo con el PNUD (2016), entre 1995 y 2015, en América Latina se experimentó una reducción de la pobreza tanto por ingresos como por porcentajes. Los países que mostraron mayor reducción fueron Argentina, Brasil, Colombia, México y Perú. Sin 
embargo, ni sus pueblos indígenas ni sus poblaciones afrodescendientes se vieron favorecidas. Esto, podría significar, en el caso de Brasil y Colombia, que a pesar de ser referencia respecto al reconocimiento constitucional de la diferencia cultural e implementación de políticas multiculturales, éstas no han sido efectivas para el combate a la pobreza. Por otro lado, Naciones Unidas (2006 citada por Antón y Rivera, 2010) afirma que la pobreza, marginalidad y exclusión social están vinculadas al racismo, discriminación racial, xenofobia y formas conexas de intolerancia, las cuales son sufridas por los pueblos indígenas y por las poblaciones afrodescendientes (Conapred, 2011a, 2011b; De Ferranti et al., 2004; Flores, 2006; Hooker, 2005, 2009, 2010; Hopenhayn, Bello y Miranda, 2006). En resumen, las poblaciones afrodescendientes de América Latina viven en condiciones de pobreza, marginación, exclusión social, y son víctimas de racismo, discriminación racial y xenofobia.

\section{Datos estadísticos}

Los datos producidos por herramientas como los censos y las encuestas de hogares, "posibilitan la obtención de una gran cantidad de indicadores demográficos, socioeconómicos y de salud, lo cual los convierte en una fuente de información muy importante" (García, 2010, p. 11). Para la cuestión afrodescendiente, la lectura de datos estadísticos sirve para el análisis y la toma de decisión del tipo de política que se debe de implementar. Hopenhayn et al. (2006, p. 25) mencionan que la aplicación de estas herramientas estadísticas y sus resultados, "tienen un innegable componente político, pues para los afectados significa la visibilización de su situación, así como una forma de reconocimiento frente a los otros. [Mientras que] para los Estados y gobiernos, el manejo de las cifras se ha vinculado muchas veces con la negación del racismo, la discriminación y la xenofobia”. Cada país establece la periodicidad en la que lleva a cabo sus conteos censales. La media en América Latina es de 10 años. Para el caso de la población afrodescendiente, algunos países incluyeron la pregunta en la ronda de censos del año 2000, otros tantos se sumaron en la ronda de 2010 y, otros, como Chile, México y Uruguay, implementaron Encuestas de Hogares y Encuestas Intercensales a media década.

Con los resultados de la ronda de 2000, Fabiana del Popolo recogió y procesó datos de ocho países (Brasil, Colombia, Costa Rica, 
Cuba, Ecuador, Guatemala, Honduras, Nicaragua). Sumó un total de 84.9 millones de afrodescendientes, equivalente a $32.8 \%$ del total de habitantes de esos países. Los resultados de la ronda de 2010 arrojaron una cifra tentativa de 150 millones de afrodescendientes, equivalente, dependiendo del organismo que haya recogido y procesado los datos, a entre 15.6 \% y $30 \%$ de la población total de la región (Antón y Del Popolo, 2008; De Ferranti et al., 2004; CIDH, 2011). A pesar de que entre 2000 y 2015 varios países implementaron metodologías, censos y encuestas, aún no se ha establecido un porcentaje certero de las poblaciones afrodescendientes que habitan en América Latina, pues no existe una metodología que proporcione información sistemática y confiable, debido al complejo tema de la identidad, autorreconocimiento, dinámicas racistas y discriminatorias.

El cuadro 1 refleja la evolución tanto de la incorporación de la variable afrodescendiente como de los porcentajes de las personas que se autorreconocen como tal. La lectura del cuadro también advierte que México, Chile y Perú, aún no han incorporado la variable afrodescendiente al censo oficial, pero realizaron ejercicios intercensales y encuestas de hogares entre la segunda ronda y la víspera de la tercera. La gráfica 1 fue realizada tomando los porcentajes del cuadro 1 y muestra que Venezuela, Brasil y Belice son los países con mayor población afrodescendiente, al presentar una media de entre $50 \%$ y 30\%; le siguen Colombia, Panamá, Costa Rica, Uruguay y Ecuador, con una media porcentual de entre $10 \%$ y $7 \%$, mientras que Chile, Honduras, México y Perú, son los más bajos, con una media de entre $1 \%$ y $2 \%$. Argentina, Bolivia, El Salvador, Guatemala, Nicaragua y Paraguay, presentan un porcentaje menor a $1 \%$. Sorpresivamente, es Venezuela y no Brasil, el país con más población que se reconoce como afrodescendiente. Esto podría responder a que el censo incluyó la categoría "moreno". Si hubieran incluido la categoría "negro", es muy probable que los resultados hubieran salido bajos. Por otra parte, Belice, a pesar de que presenta pocos derechos conquistados, como se verá en la siguiente sección, ocupa el tercer lugar, mientras que Colombia, a pesar de ser referencia en cuanto a derechos conquistados y organización, ocupa el cuarto lugar. Finalmente, Guatemala, junto con Bolivia son de los países con porcentajes más bajos, posiblemente por la preponderancia de población indígena. 
- CUADRO 1. Ronda de censos de 2000 y 2010 de países latinoamericanos

\begin{tabular}{|c|c|c|c|c|}
\hline PAÍs & AÑo & VARIABLE AFRODESCENDIENTE & TOTAL & PORCENTAJE \\
\hline \multirow{2}{*}{ Argentina } & 2000 & No & 0 & $0.0 \%$ \\
\hline & 2010 & Sí & 149493 & $0.37 \%$ \\
\hline \multirow{2}{*}{ Belice } & 2000 & No & 0 & $0.0 \%$ \\
\hline & 2010 & Sí & 103099 & $33.36 \%$ \\
\hline \multirow{2}{*}{ Bolivia } & 2001 & No & 0 & $0.0 \%$ \\
\hline & 2012 & Sí & 16324 & $0.16 \%$ \\
\hline \multirow{2}{*}{ Brasil $^{a}$} & 2000 & Sí & 75639763 & $44.55 \%$ \\
\hline & 2010 & Sí & 96795294 & $50.70 \%$ \\
\hline \multirow{2}{*}{ Chile } & 2002 & No & 0 & $0.0 \%$ \\
\hline & 2014 & Encuesta de caracterización & 8415000 & $0.10 \%$ \\
\hline \multirow{2}{*}{ Colombia $^{b}$} & 1993 & Sí & Sin datos & Sin datos \\
\hline & 2005 & Sí & 4311757 & $10.40 \%$ \\
\hline \multirow{2}{*}{ Costa Rica $^{c}$} & 2000 & Sí & 72784 & $1.9 \%$ \\
\hline & 2011 & Sí & 334437 & $7.8 \%$ \\
\hline \multirow{2}{*}{ Ecuador } & 2001 & Sí & 604009 & $4.97 \%$ \\
\hline & $2010^{\mathrm{d}}$ & Sí & 1041559 & $7.20 \%$ \\
\hline \multirow{2}{*}{ El Salvador } & 2000 & No & 0 & $0 \%$ \\
\hline & 2007 & Sí & 7441 & $0.10 \%$ \\
\hline \multirow{2}{*}{ Guatemala } & 2002 & Sí & 504000 & $0.04 \%$ \\
\hline & 2010 & Sí ${ }^{*}$ como indígenas ${ }^{\mathrm{e}}$ & Sin datos & Sin datos \\
\hline \multirow{2}{*}{ Honduras } & 2001 & Sí & 5881800 & $0.90 \%$ \\
\hline & 2011 & Sí & Sin datos & $2 \%$ \\
\hline \multirow{3}{*}{ México } & 2000 & No & 0 & $0,0 \%$ \\
\hline & 2010 & No & 0 & $0,0 \%$ \\
\hline & 2015 & Encuesta Intercensal & 1381853 & $1.2 \%$ \\
\hline \multirow{2}{*}{ Nicaragua } & 1995 & No & No & $0.0 \%$ \\
\hline & 2005 & Sí & 2316100 & $0.45 \%$ \\
\hline \multirow{2}{*}{ Panamá } & 2000 & No & 0 & $0.0 \%$ \\
\hline & 2010 & Sí & 31328900 & $9.20 \%$ \\
\hline \multirow{2}{*}{ Paraguay } & 2002 & No & 0 & $0.0 \%$ \\
\hline & 2012 & Sí & 801300 & $0.15 \%$ \\
\hline \multirow{2}{*}{ Perú } & 2007 & No & 0 & $0.0 \%$ \\
\hline & 2010 & Encuesta de Hogares & Sin datos & $1.5 \%$ \\
\hline \multirow{2}{*}{ Uruguay } & 2004 & No & 0 & $0.0 \%$ \\
\hline & 2011 & Encuesta de Hogares & 25507400 & $7.70 \%$ \\
\hline \multirow{2}{*}{ Venezuela $^{f}$} & 2001 & No & 0 & $0.0 \%$ \\
\hline & 2011 & Sí & 15457217 & $53.40 \%$ \\
\hline
\end{tabular}

aSegún el informe del PNUD (2012, p. 17), los censos realizados por Brasil, a excepción de las variables de salud, son "de los pocos de la región que incluye preguntas sobre los ingresos, tanto laborales como totales". 'Existe un Proyecto de Ley para un Censo detallado de personas afrodescendientes de septiembre de 2015. 'La cifra total se reparte así: afrodescendientes: 184 118; negros: 28 607, y mulatos: 15551 (PNUD, 2013). dEste censo ofrece abundante información de afrodescendientes en ámbitos como la educación, el empleo (no incluyeron ingresos), vivienda e infraestructura básica (García, 2010).

eLos garífuna han sido englobados en los censos nacionales en la variable indígena (Agudelo, 2011).

fLa variable incluye las denominaciones de negro, mulato, afrovenezolano y moreno.

Fuente: Cuadro de elaboración propia con datos de: Agudelo (2011); Antón y Del Popolo (2008); Antón y Rivera (2010); DANE (2005); Del Popolo (2013); DIGESTYC (2008); ENAHO (2010); García (2010); Hooker et al. (2010); IBGE (2010); López, 2018; INE-G (2002); INE-H (2001); INE-V (2011); INE-U (2011); INEC-C (2011); INEC-E (2010); INEC-N (2005); PNUD (2012); PNUD (2013); Rangel (2009); Rodríguez y Antón (2014). 


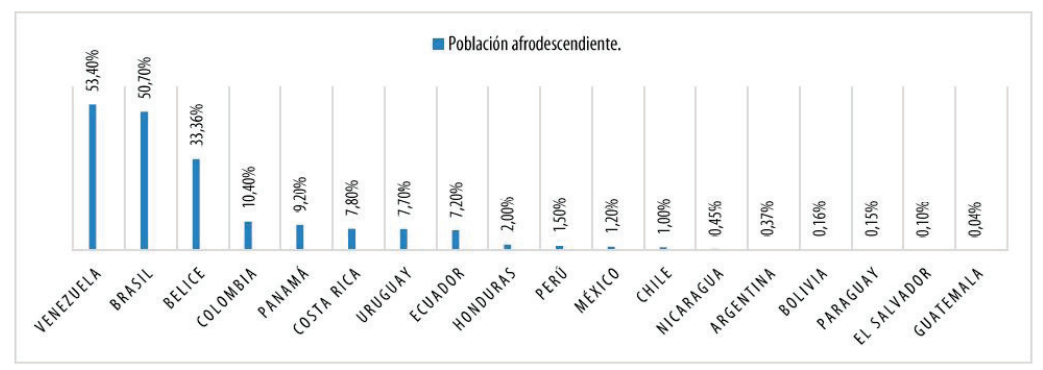

Fuente: gráfica de elaboración propia con los datos censales.

\section{DERECHOS CONQUISTADOS POR LAS LUCHAS AFRODESCENDIENTES DE AMÉRICA LATINA}

Los derechos que la población afrodescendiente organizada ha logrado conquistar ${ }^{1}$ para incluirse al desarrollo del Estado nación son diversos. Para identificarlos, se tomó como referencia el contexto norteamericano con textos de Levy (1997) y Kymlicka (1995, 2007), y para el contexto latinoamericano, se usaron textos de Agudelo (2010, 2015), Cuisset (2014), Hooker $(2005,2010,2011)$ y Van Cott (2000a, 2000b, 2001), entre otros. La confluencia de estas lecturas permitió organizar las políticas multiculturales implementadas en América Latina de la siguiente manera:

1. Políticas multiculturales: reconocimiento constitucional, derechos de la propiedad colectiva de la tierra, legislación y herramientas contra la discriminación racial.

2. Políticas de acción afirmativa: ${ }^{2}$ educación, desarrollo social, salud, trabajo, representación en y creación de instituciones políticas y culturales, reconocimiento simbólico-cultural, legislación.

3. Políticas Públicas.

El artículo esboza un marco de los principales derechos conquistados en la región, por tanto, es posible que algunas políticas

\footnotetext{
${ }^{1}$ Con derechos conquistados me refiero a la formulación e implementación de políticas multiculturales, políticas de acción afirmativa y políticas públicas formuladas específicamente para la población afrodescendiente.

${ }^{2}$ De acuerdo con el material revisado, éstas son las áreas en las que más se han implementado en la región.
} 
multiculturales, políticas de acción afirmativa, o políticas públicas no sean mencionadas en este texto. Sin embargo, las que están señaladas son las más significativas (Rangel, 2016). Es necesario también tener presente que las políticas aplicadas en cada país responden a contextos y coyunturas específicas, como la presión por movilizaciones significativas o coyunturas internacionales como las cumbres de Santiago y de Durban, el Año o el Decenio Internacional del Afrodescendiente.

\section{Políticas multiculturales}

En los cuadros 2, 3 y 4 se observan las políticas multiculturales y la temporalidad en las que se han implementado. Los países que, hasta 2017, no reconocían constitucionalmente a su población afrodescendiente, aunque algunos sí mencionan su diversidad cultural, son: Argentina, Belice, Chile, Costa Rica, El Salvador, México, Panamá, Paraguay, Perú, Uruguay y Venezuela. Por ende, tampoco concedieron derechos como la propiedad colectiva de la tierra. Esta demanda no cobró fuerza en México por la creación de tierras ejidales y comunales durante la reforma agraria de las primeras décadas del siglo XIX (Burguete y Mayor, 2003; Lewis, 2012).

- CUADRO 2. Reconocimiento constitucional en América Latina

\begin{tabular}{|c|c|c|c|}
\hline País & Año & Diversidad & Afrodescendientes \\
\hline Argentina & 1994 & Sí & No \\
\hline Belice & No & No & No \\
\hline Bolivia & 1994 & Sí & Sí \\
\hline Brasil & 1988 & Sí & Sí \\
\hline Chile & No & No & No \\
\hline Colombia & 1991 & Sí & Sí \\
\hline Costa Rica & 2015 & Sí & No \\
\hline Ecuador $^{\mathrm{a}}$ & 2008 & Sí & Sí \\
\hline El Salvador & No & No & No \\
\hline Guatemala & 1988 & Sí & Sí (Pueblo indígena) \\
\hline Honduras & 1982 & Sí & Sí (Pueblo indígena) \\
\hline México & 1992 & Sí & No \\
\hline Nicaragua & 1988 & Sí & Sí (Comunidades étnicas) \\
\hline Panamá & No & Sí & No \\
\hline Paraguay & 1992 & Sí & No \\
\hline Perú & 1993 & Sí & No \\
\hline Uruguay & No & No & No \\
\hline Venezuela & 1999 & Sí & No \\
\hline
\end{tabular}

aLas poblaciones afrodescendientes de Guatemala, Honduras, Nicaragua, Ecuador tienen los mismos derechos que los pueblos indígenas.

Fuente: cuadro de elaboración propia con datos de Agudelo (2011, 2015); Antón y Rivera (2010); Arias (2015); Becerra et al. (2010); Buffa y Becerra (2012); Const. (1999); Const. (2009); Const. (2005); Const. (1949); Const. (2008); Const. (1983); Const. (1985); Const. (1982); Const. (1967); Const. (1972); Const. (1917); Const. (1987); 
El reclamo se centra en la defensa de las tierras contra megaproyectos, así como en la conservación y protección del ecosistema por medio de programas ecológicos (López, 2017). Respecto al combate a la discriminación racial, Brasil, Colombia, Ecuador y Perú han aplicado más instrumentos, mientras que Belice, Chile, Costa Rica, El Salvador, Paraguay y Venezuela lo han hecho en menor proporción. México muestra una actividad significativa. Sin embargo, ningún instrumento ha sido dirigido hacia la población afromexicana. Pese a ello, es necesario resaltar la ardua tarea que ha realizado el Consejo Nacional para Prevenir y Eliminar la Discriminación (Conapred).

Cuadro 3. Reconocimiento de la propiedad colectiva de la tierra

\begin{tabular}{|r|c|c|c|}
\hline País & Titulo & Año & Instrumento jurídico \\
\hline Argentina & No & No & No \\
\hline Belice & No & No & No \\
\hline Bolivia & Sí & 2009 & Artículo 395 de la Constitución Política de 2009. \\
\hline Brasil & Sí. & 1988 & Artículo 68 de la Constitución Política de 1988, regulado por el Decreto 4887 \\
de 2013.
\end{tabular}

Fuente: cuadro de elaboración propia con datos de Agudelo (2011); Antón y Rivera (2010); Arias (2015); Becerra, Buffa, Celton et al. (2010); Buffa y Becerra (2012); CIDH (2011); Const., (1985); Const., (1987); García (2010); Hopenhayn et al. (2006); Hooker et al. (2010); Lechini (2008); PNUD (2012); Muteba y Dougé Prosper (2014); Rodríguez y Antón (2014); SEGIB-PNUD (2009).

Cuadro 4. Legislación y herramientas contra la discriminación racial

Sí: Argentina, Bolivia, Brasil, Chile, ${ }^{a}$ Colombia, Costa Rica, Ecuador, Guatemala, Honduras, México, Nicaragua, Panamá, Perú, Uruguay, Venezuela.

No: Belice, El Salvador, Paraguay.

aSi bien es una ley antidiscriminatoria, su foco es la intolerancia a la homosexualidad. No hace alusión a la discriminación racial, pues lo engloba en "todo tipo de discriminación".

Fuente: cuadro de elaboración propia con datos de Agudelo (2011); Agudelo (2015); Antón y Rivera (2010); Arias (2015); Buffa y Becerra (2012); Becerra et al. (2010); CIDH (2011); CONAPRED (2015); COPRED (2016); Embajada de la República Bolivariana de Venezuela en Estados Unidos (2012); Excélsior (2014); Hopenhayn et al. (2006); Hooker et al. (2010); Lechini (2008); Muteba y Dougé-Prosper (2014); Rangel (2016); PNUD (2012); Rodríguez y Antón (2014); SEGIB-PNUD (2009). 


\section{Políticas de acción afirmativa}

\section{para afrodescendientes en América Latina}

La acción afirmativa pretende contribuir con la implementación de políticas específicas que dan una determinada ventaja o preferencia a la reducción de desigualdades e inequidades, con el objetivo de mejorar la situación en la que se encuentran grupos que han sido víctimas de injusticias sociales (SEGIB-PNUD, 2009). El cuadro 5 tiene como finalidad construir una panorámica general de las acciones afirmativas implementadas, para poder identificar a los países que tienen más actividad en este ámbito y el área a la que han dado prioridad. Es posible que se hayan omitido algunas variables no contenida en las fuentes consultadas. Sin embargo, como se mencionó anteriormente, la encomienda es dibujar un mapa general.

Se puede identificar que Honduras es el país con más actividad en la variable simbólica/cultural, mientras que Ecuador aplica más acciones en el área de desarrollo social. Por otro lado, Brasil, Colombia y Ecuador han destinado más atención a la educación. Brasil se enfoca en el acceso a la educación superior y técnica, en instituciones públicas o privadas, por medio del sistema de cupos; Colombia lo hace con becas, créditos y el sistema de cupos, y Ecuador con créditos o becas. En cuanto a la representación en instituciones políticas y culturales, Brasil, Colombia y Ecuador son los que llevan la batuta. En el área de salud, el liderazgo lo tienen Brasil y Uruguay. En cuanto al trabajo, Brasil, Colombia y Panamá han formulado más acciones afirmativas. El único país que ha implementado acción afirmativa en turismo es Honduras, mientras que Brasil y México lo han hecho en el área judicial. Se identifica que Brasil, Colombia y Ecuador, clasificados como los países con movimientos indígenas más exitosos y como los que han implementado más políticas multiculturales para afrodescendientes (Sieder, 2002; Van Cott, 2001), también han aplicado más acciones afirmativas. México muestra una actividad importante, pues presenta acciones en cinco de las ocho variables presentadas en este artículo. 
- Cuadro 5. Políticas de acción afirmativa

\begin{tabular}{|c|c|c|c|c|c|}
\hline País & $\begin{array}{l}\text { Simbólico } \\
\text { Cultural }^{a}\end{array}$ & $\begin{array}{l}\text { Desarrollo social y } \\
\text { derechos humanos }^{b}\end{array}$ & Educaciónc & Salud $^{d}$ & $\begin{array}{c}\text { Representación } \\
\text { en instituciones políticas } \\
\text { y culturales }\end{array}$ \\
\hline Argentina & Sí & No & No & No & No \\
\hline Belice & Sí & No & No & No & No \\
\hline Bolivia & Sí & No & No & No & Sí \\
\hline Brasil & Sí & Sí & Sí & Sí & Sí \\
\hline Chile & No & No & No & No & No \\
\hline Colombia & Sí & Sí & Sí & Sí & Sí \\
\hline Costa Rica & Sí & No & Sí & No & Sí \\
\hline Ecuador & Sí & Sí & Sí & Sí & Sí \\
\hline Salvador & Sí & No & No & No & No \\
\hline Guatemala & Sí & No & No & No & Sí \\
\hline Honduras & Sí & Sí & Sí & No & Sí \\
\hline México ${ }^{f}$ & Sí & Sí & Sí & No & Sí \\
\hline Nicaragua & Sí & No & No & Sí & No \\
\hline Panamá & Sí & Sí & Sí & No & No \\
\hline Paraguay & No & No & No & No & No \\
\hline Perú & Sí & Sí & Sí & No & Sí \\
\hline Uruguay & Sí & Sí & Sí & Sí & Sí \\
\hline Venezuela & Sí & Sí & Sí & No & Sí \\
\hline
\end{tabular}

'Día nacional del afrodescendiente y de su cultura, día contra la discriminación racial, monumentos de héroes, acciones para recuperar la memoria histórica, fiestas nacionales, reconocimiento de expresiones culturales como las danzas, reconocimiento de héroes afrodescendientes, reconocimiento y perdón de los Estados respecto a las situaciones de esclavitud, racismo y discriminación, declaración de patrimonio cultural e inmaterial. 'Programas para promover la ciudadanía plural y la inclusión, Programas de desarrollo para reducir la pobreza y promover inclusión, protección para zonas afrodescendientes con problemas ambientales, Planes Nacionales para la igualdad de género, Planes Nacionales para la protección y garantía de los Derechos Humanos, sistemas de indicadores sociales, medidas reparatorias para víctimas de desplazamiento. ${ }^{c}$ Cupos y cuotas con un porcentaje o número específico, créditos y becas, totales y parciales, para estudiar en nivel superior, financiamiento de proyectos educativos para instituciones con más de $50 \%$ de estudiantes afrodescendientes e indígenas, incorporación de la historia afrodescendiente al currículo, financiación para formación de profesores, cátedras de estudios afrodescendientes, apoyos financieros para

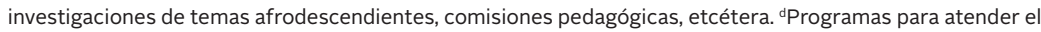
VIH/SIDA, promoción de la medicina tradicional. e Representación en instituciones gubernamentales políticas y culturales, en partidos políticos, nombramiento de cargos públicos, espacios en la televisión y otros medios de comunicación, oficinas de enlace, cupos del 20\%, curules y representaciones en instituciones legislativas y cupos del $20 \%$ en instituciones judiciales. fMéxico argumenta que la inexistencia de un sujeto de derechos no permite generar acciones afirmativas. Sin embargo, las identificadas han sido implementadas por instituciones académicas (simbólica/cultural y educación).

- Cuadro 5 bis. Políticas de acción afirmativa

\begin{tabular}{|r|c|c|c|}
\hline \multicolumn{1}{|c|}{ País } & Trabajo $^{\text {a }}$ & Turismo $^{\text {b }}$ & Judicial $^{\text {c }}$ \\
\hline Argentina & No & No & No \\
\hline Belice & No & No & No \\
\hline Bolivia & No & No & No \\
\hline Brasil & Sí & No & Sí \\
\hline Chile & No & No & No \\
\hline Colombia & Sí & No & No \\
\hline Costa Rica & No & No & No \\
\hline Ecuador & No & No & No \\
\hline Salvador & No & No & No \\
\hline Guatemala & No & No & No \\
\hline Honduras & No & Sí & Sí (Guerrero) \\
\hline Micaragua & No & No & No \\
\hline
\end{tabular}




\begin{tabular}{|r|c|c|c|}
\hline \multicolumn{1}{|c|}{ País } & Trabajo $^{\mathrm{a}}$ & Turismo $^{\mathrm{b}}$ & Judicial $^{\mathrm{c}}$ \\
\hline Panamá & Sí & No & No \\
\hline Paraguay & No & No & No \\
\hline Perú & No & No & No \\
\hline Uruguay & No & No & No \\
\hline Venezuela & No & No & No \\
\hline
\end{tabular}

${ }^{a}$ Cuotas en empresas, revisión de contratos, programas para trabajadores rurales, contratos para mujeres afrodescendientes. ${ }^{\circ}$ Proyectos de etnoturismo o de turismo en sitios de memoria histórica. Posiblemente Brasil y Colombia tengan políticas de acción afirmativa en esta área. Sin embargo, en el material revisado no identifiqué ninguna. 'Son sujetos especiales de protección constitucional en el Tribunal constitucional, recepción de ayuda como víctimas del desplazamiento forzado en la Corte Constitucional, o programas de fianzas.

Fuente: Cuadro de elaboración propia con datos de Agudelo (2011); Antón y Rivera (2010); Arias (2015); Becerra et al. (2010); Buffa y Becerra (2012); CIDH (2011); Hopenhayn et al. (2006); Hooker (2010); Lechini (2008); PNUD (2012); Muteba y Dougé-Prosper (2014); Rangel (2016); Rodríguez y Antón, (2014); SEGIBPNUD (2009). Para consultar políticas de acción afirmativa a detalle, ver López (2017, pp. 313-318, López, 2018, pp. 21-22).

\section{Políticas públicas para afrodescendientes en América Latina}

Entiendo por políticas gubernamentales las acciones que un gobierno emprende, unidireccionalmente, para resolver ciertas necesidades de un sector específico de la población (Aguilar, 1992), y por políticas públicas, las acciones formuladas para resolver las necesidades de un sector específico de la población, pero de manera bilateral; es decir, con la participación no solamente del gobierno y sus instituciones, sino también del sector poblacional que sufre el problema público (Canto, 2002). Las luchas afrodescendientes latinoamericanas y sus reivindicaciones políticas emergieron a mediados de la década de los ochenta (Agudelo, 2010) con el antecedente de la organización indígena y en el contexto de un mundo globalizado. En su recorrido, algunas han logrado llegar a la etapa de participación y formulación de políticas públicas, sobre todo en la segunda parte de la década de los noventa y la primera parte de la década del nuevo mileno. Por ejemplo: Brasil (educación, igualdad racial, laboral, género, salud); Colombia (educación, diversidad cultural y garantía de derechos); Ecuador (educación, salud, empleo, vivienda, derechos humanos), y Nicaragua (salud, educación, lengua). La movilización afromexicana se encuentra en pleno recorrido para lograr ese paso (López, 2017, pp. 200-202). 


\section{ORGANIZACIONES Y REDES: INTERACCIÓN NACIONAL Y TRANSNACIONAL}

Las organizaciones constituidas por los afrodescendientes son clave en sus procesos de emergencia y organización, pues se han convertido en la voz de su lucha y movilización. Por tanto, también fungen como actores sociales y políticos de carácter local, nacional e internacional, al interactuar con instituciones gubernamentales, organizaciones de apoyo, civiles o de desarrollo, organizaciones afrodescendientes de otros países y Organismos Internacionales.

Previo a 1980, cuando el marco multicultural estaba cobrando auge en la región, sólo se había constituido $2 \%$ de las organizaciones que actualmente existen, en 1980 ya había 10\%, en 1990, periodo de auge, las organizaciones se incrementaron en 35\% y en la década de 2000, cuya primera mitad es clasificada como de consolidación, ya se había constituido 54\% de las organizaciones (Kymlicka, 2007; Le Bot, 2009; SEGIB-PNUD, 2009). Vemos que el auge y la constitución de organizaciones entre 1990 y 2000 se correlaciona con el periodo de auge y consolidación de las luchas afrodescendientes, en el marco de la cumbre preparatoria de Santiago de Chile $^{3}$ y la cumbre de Durban (SEGIB, 2016, p.19).

Respecto al caso mexicano, sólo una organización (México Negro) se formó a finales del periodo de auge, específicamente, en 1997. Este tiempo coincide con el inicio de la organización política afromexicana, representada por el Primer Encuentro de Pueblos Negros. La mayoría de las organizaciones involucradas en la movilización terminaron de constituirse hacia el 2008 (López, 2017, pp. 132-138), tiempo que entra en el periodo de más constitución de organizaciones, aunque sobrepasa la temporalidad en la que finaliza el periodo de consolidación de movilizaciones (2005) que establece Le Bot (2009). Este desajuste de tiempos entre la constitución de organizaciones y el periodo de consolidación de las movilizaciones se relaciona con la tardía gesta y emergencia del afromexicano como sujeto políticamente organizado. Una característica de las organizaciones afromexicanas que también explica este retraso, es que no existe una correlación de fuerzas al interior, se han experimentado

3Aquí se acuña afrodescendiente para referirse a poblaciones de origen africano de América Latina y el Caribe. 
fragmentaciones y antagonismos que responden a: la movilización se ha politizado por la oportunidad de acceder a recursos económicos de diversos orígenes (el Estado, fundaciones, ONG, instituciones académicas) o beneficios políticos, y por la experiencia y previa formación política de algunos líderes, quienes, por tanto, tienen posicionamientos partidarios e intereses diferentes. Esto también influye en la capacidad de construir una agenda unificada (López, 2018).

De acuerdo al primer relevamiento de organizaciones afrodescendientes realizado por la SEGIB y el PNUD (2009), los obstáculos a los que se enfrentan las organizaciones son: poca formación en procesos de liderazgo y de organización, pocos recursos económicos para la financiación de sus actividades, falta de interacción entre organizaciones que no están afiliadas a redes y ausencia y poco acceso a herramientas tecnológicas, invisibilidad por falta de promoción y presencia de la historia afrodescendiente en el currículo escolar. Por otro lado, las fortalezas identificadas son: concientización de la necesidad de organizarse nacional e internacionalmente, la presencia de la temática de género ha llevado a formar redes transnacionales importantes, como la Red de mujeres Afrolatinoamericanas y Afrocaribeńas de la diáspora. Lo que, a su vez, ha resultado en el empoderamiento de grupos de mujeres y en la contribución cultural a la identidad afrolatina (SEGIB-PNUD, 2009, pp. 45-46).

Las organizaciones afromexicanas experimentan los cinco obstáculos. Por ejemplo, la única formación de liderazgo y organización formal que se llevó a cabo en la década de 2000, fue la que recibieron en Honduras representantes afromexicanos en vísperas de la constitución de la organización ODECA. Por otro lado, el Instituto de Liderazgo Simone de Beauvoir (ILSB) y el Fondo Semillas, son las dos organizaciones de apoyo que, a partir de finales de 2014, comenzaron a desarrollar programas de liderazgo para mujeres. El empoderamiento de un grupo de mujeres afromexicanas les permitió constituir el proyecto Cátedra Itinerante de Mujeres Afromexicanas, el cual también intenta contribuir a las formaciones de liderazgo. Vemos que la formación de liderazgos no fue impulsada por organizaciones (López, 2017, pp. 203-208).

La falta de recursos para financiar actividades también está presente. Existe intervención y participación de instituciones gubernamentales 
y de organizaciones de desarrollo. Por otra parte, algunos líderes han aprovechado la infraestructura y el apoyo económico de las instituciones gubernamentales a las que pertenecen, para llevar a cabo actividades de la movilización. Esto puede condicionar y comprometer a la movilización con el partido al que pertenezcan (López, 2017, pp. 203-208).

Si bien los líderes y miembros de las organizaciones han contactado con otras organizaciones de la región, su interacción es débil; por tanto, la interacción y contacto con organizaciones que no forman parte de alguna red es aún más débil. El poco uso de los nuevos dispositivos es también palpable. Es indiscutible que la mayoría de los líderes utiliza las redes sociales para promover eventos o entrar en contacto e interacción. De hecho, Hoffmann y Lara (2012) han señalado que la externalización de la movilización fue posible gracias a las nuevas herramientas tecnológicas como el Internet. Sin embargo, no todos los líderes las utilizan, algunos usan sólo instrumentos básicos y otros recurren a ellos con poca frecuencia (Notas personales tomadas durante trabajo de campo en Cuajinicuilapa, Guerrero, en noviembre y diciembre de 2013; diciembre de 2014, y enero, agosto y noviembre de 2015). Por tanto, existe la necesidad de formar nuevos liderazgos y capacitarlos de cara a los retos y necesidades actuales. Esto puede ser un factor que resulte, y a la vez, explique la débil presencia de la movilización en la región.

Durante el proceso de constitución de las organizaciones se fueron gestando redes nacionales y transnacionales que dieron impulso a las luchas sociales afrodescendientes (SEGIB, 2016), a la vez que, irónicamente, contribuyeron a la internacionalización o expansión del neoliberalismo multicultural, cuando comenzaron a interactuar con "diversos actores, entre ellos, organismos internacionales, agencias multilaterales, movimientos indígenas, académicos y académicas, actores políticos, entre otros" (García, 2016, p. 15). El concepto de neoliberalismo multicultural se refiere a la interacción de las políticas multiculturales que surgieron entre 1960 y 1980, y a las reformas políticas y económicas de corte neoliberal implementadas desde 1970 , pero que comenzaron a surtir efecto hasta 1980, y su principal característica es lo que Charles Hale llama el yes, but; es decir, otorgar un derecho pero poner requisitos o condiciones que, finalmente, no permiten ponerlo en práctica (Hale, 2002, 2005). Las redes afrodes- 
cendientes de América Latina y el Caribe ${ }^{4}$ se fueron tejiendo entre las décadas de los ochenta y los noventa, con el objetivo de crear vínculos para responder a las necesidades de los afrodescendientes, fortalecer las demandas respecto a mejoras sociales, derechos culturales, políticos y económicos (Buffa y Becerra, 2012), para constituir "la oposición que se consolidó frente a la globalización, sobre todo en cuanto a sus aspectos económicos" (Agudelo, 2010, p. 76), para formular una agenda regional dirigida a la reducción del racismo y la discriminación, y para impulsar el empoderamiento del colectivo afrodescendiente (Rangel, 2009).

Durante la conferencia preparatoria de Santiago de Chile, en 2000, en vísperas de la conferencia de Durban, las organizaciones acordaron hacer lobbies ante los Organismos para incidir en las orientaciones políticas hacia los sectores afrolatinoamericanos (Rangel, 2009). De hecho, Buffa y Becerra (2012) afirman que la conferencia preparatoria de Santiago de Chile fue un evento cohesionador e hito para la formación de las redes. Además, en esta conferencia se adoptó oficialmente el termino Afrodescendiente. Lao Montes (2009) menciona, como anécdota, que al final de una de las reuniones de la Cumbre, Romero Rodríguez, de la organización Mundo Afro de Uruguay, declaró la famosa frase de: "Entramos Negros y salimos Afrodescendientes".

Así pues, durante la conferencia de Durban (2001), se configuró el liderazgo e integración colectiva a nivel local, nacional y transnacional, la identidad política de afrodescendiente y una agenda política afrolatinoamericana (Agudelo, 2010; Díaz, 2015; Hopenhayn et al., 2006; Lao Montes, 2009). Sin embargo, Díaz (2015, p. 9) afirma que la agenda "se distorsionó por la intervención de la derecha internacional, los mecanismos institucionales de las grandes corporaciones, las formalidades de los organismos multilaterales, la burocracia enquistada y fundamentalmente la mentalidad neoliberal de cierto liderazgo que percibió en los financiamientos una oportunidad para resolver sus intereses particulares". Lo que denun-

\footnotetext{
${ }^{4}$ Algunas de las redes que tomaron más impulso fueron; la Organización Negra Centroamericana (ONECA), de 1994; Afroamérica XXI, de 1996, y la Red de Oficinas Regionales para el Análisis de Políticas de Equidad Racial (ORAPER), de 2004; Parlamento Negro de las Américas, de 2008, resultado de reuniones anuales de congresistas afrodescendientes de la región que comenzaron en 2003, y la Articulación Regional Afrodescendiente de América Latina y el Caribe (ARAAC), de 2012.
} 
cia es la operación del multiculturalismo neoliberal aderezado con burocracia del Estado.

La Red de Mujeres Afrolatinoamericanas y Afrocaribeñas de 1992, que articula reivindicaciones de género y raza (Agudelo, 2010), y la Alianza Estratégica de Afrodescendientes de América Latina y el Caribe de 2000, fueron redes transnacionales clave del movimiento regional afrodescendiente (Lao Montes, 2015). Una delegación de mujeres afromexicanas participó en la Primera Cumbre de Lideresas Afrodescendientes de las Américas de 2015, organizada por la Red de Mujeres Afrolatinoamericanas y Afrocaribeńas. La asistencia de la delegación fue significativa para el proceso de empoderamiento de la mujer afromexicana y para el posicionamiento y visibilización de la movilización, pues ha tenido, además de interacciones puntuales y contactos individuales con otros líderes afrodescendientes, mencionados en el capítulo anterior, poca presencia a nivel regional (López, 2017).

México también entró tarde a este proceso de intercambios, interconexiones y retroalimentación transnacional, pues va en consonancia con la constitución de las organizaciones. Cuando se comenzaron a gestar las redes transnacionales en las décadas de los ochenta y los noventa del siglo XX, la única organización afromexicana constituida era México Negro. Por otro lado, solamente Socpinda pertenece a la Red Iberoamericana de Organismos y Organizaciones contra la Discriminación (RIOOD), mientras que el grupo de mujeres afromexicanas que forman parte de la Cátedra Itinerante de Estudios Afromexicanos, pertenecen a la Red de Mujeres Afrolatinoamericanas y Afrocaribeńas de la Diáspora. Por tanto, aunque la movilización afromexicana se ha apoyado y ha tenido momentos de visibilidad por los contactos e interacciones con líderes y organizaciones afrolatinoamericanas, de manera general, no ha aprovechado esta herramienta de movilización, ya que vemos que la mayoría de las organizaciones no pertenecen a ninguna red transnacional. Cabe señalar que en este punto vuelve a destacar el empoderamiento de las mujeres afromexicanas, por su incorporación a la Red de Mujeres Afrolatinoamericanas y Afrocaribeñas.

Las redes transnacionales y la movilización afromexicana coinciden en que el financiamiento de algunas de sus actividades depende 
de organismos internacionales, agencias de cooperación, fundaciones o instituciones financieras y, por tanto, su operación también depende, en cierto grado, del estado de su relación con dichos actores. Por otro lado, la actividad de las redes se ve condicionada a la presencia y disponibilidad de sus líderes e integrantes, pues de acuerdo con sus intereses, algunas veces "han optado o se han visto obligados a concentrarse en las luchas nacionales; [esto es] otro factor que explica las apariciones y desapariciones de dichos espacios transnacionales de movilización" (Agudelo, 2015, p. 18).

Las organizaciones, de manera individual o en red, han trabajado también con Organismos Internacionales. Según SEGIB-PNUD (2009) de $100 \%$ de su muestra, 52\% de las organizaciones afrodescendientes trabajaba con Organismos Internacionales. El segundo relevamiento de organizaciones de la SEGIB (2016), ${ }^{5}$ muestra que las organizaciones que tienen más interacción son: Colombia (22), Ecuador (15), Costa Rica (9), Panamá (7), Honduras y Perú (6), Uruguay y Argentina (4), y México (3). En Brasil, Chile Cuba, Guatemala, El Salvador, Nicaragua, Paraguay, República Dominicana y Venezuela registraron de 2 a 0 organizaciones en interacción con organismos internacionales. Estas cifras refrendan la fortaleza de movimientos como el colombiano y la debilidad en el plano internacional de la movilización afromexicana.

\section{CAMBIOS SOCIALES POR LA IMPLEMENTACIÓN DE POLÍTICAS MULTICULTURALES: COLOMBIA, BRASIL Y HONDURAS}

Esta sección busca situar, con tres ejemplos específicos, los cambios sociales que muestran las naciones de Brasil, Colombia y Honduras, con las políticas multiculturales que han adoptado sus países. Brasil y Colombia cuentan con una población numéricamente significativa en relación con Honduras y México, y son catalogados como hito y referencia de las movilizaciones afrodescendientes en la región (Agudelo, 2010b; Buffa y Becerra, 2012). Honduras, aunque

${ }^{5}$ La SEGIB envía un formulario para recoger información vía e mail a todas las organizaciones afrodescendientes de América Latina que estén dentro una base de datos proporcionada por el BID, SEGIB y UNESCO. Por tanto, los resultados dependen de las organizaciones que respondan a la convocatoria. 
con población numéricamente menor, experimenta una movilización políticamente fuerte y organizada (Agudelo, 2015). Así pues, aunque comparten demandas, cada movilización tiene sus propias especificidades y características. Veamos si la aplicación de políticas multiculturales ha supuesto una verdadera inclusión social, política, económica y cultural al interior del Estado nación.

\section{Brasil}

El retorno a la democracia y la configuración de un nuevo contexto político que experimentó Brasil en 1985 permitió la visibilidad de procesos organizativos, culturales y políticos gestados al interior de la movilización negra, así como "el surgimiento de nuevas organizaciones negras” (Agudelo, 2015, p. 7). Brasil fue uno de los primeros países latinoamericanos en experimentar el "multiculturalismo constitucional” (Van Cott, 2000a), pues prietos y pardos fueron reconocidos en la Constitución de 1988, la cual estableció que el país tiene una base pluricultural y multiétnica, y penalizó y proscribió actos racistas (Agudelo, 2015; Buffa y Becerra, 2012).

$\mathrm{Al}$ reconocimiento constitucional y la penalización del racismo, le precedieron la formulación de políticas multiculturales, como la legislación que otorgó derechos territoriales a los Quilombolas, y políticas de acción afirmativa, como la creación de espacios institucionales y la aplicación de herramientas estadísticas socioeconómicas. Estas acciones permitieron que activistas y líderes negros se posicionaran en instituciones gubernamentales, y en el contexto social, se desarrollaron "expresiones con mayor énfasis en las reivindicaciones culturales" (Agudelo, 2015, p. 7).

Basado en los resultados de los indicadores sociales del Instituto Brasileiro de Geográfía e Estadística de 2000, Sansone (s/a) analizó el periodo de 1992 a 1999, y comenta que, efectivamente, los índices de pobreza absoluta, como la mortalidad infantil y el analfabetismo mostraron una reducción. Sin embargo, las diferencias en la calidad de vida persistieron. Además, desde una visión macro del país, se podía identificar un declive en la calidad de la educación pública, mala distribución del ingreso, reducción del empleo formal, y un aumento en las brechas salariales y en las clases sociales. En este marco, "los grupos oficialmente definidos como morenos, pardos y prietos, y aún más, aquéllos definidos como negros, presentan re- 
sultados peores que aquéllos definidos como blancos" (Sansone, s/a, párrafo 8 , traducción propia). Entonces, Sansone (s/a) afirma que lo que Brasil necesita es un movimiento antirracista que reconozca todas las variedades de la negritud, ya que, como menciona Appiah (1994), lo negro puede ser experimentado de muchas maneras.

Paixao (2010) analizó el impacto que tuvo la aplicación de políticas multiculturales entre 1995 y 2006, en variables como evolución demográfica, educación, empleo, indigencia y pobreza. Menciona que, demográficamente, la población prieta y parda aumentó. Sin embargo, las tasas de mortalidad se mantuvieron altas. En cuanto a educación, hubo un balance positivo al reducirse la brecha de los años de estudios entre blancos, prietos y pardos. Por otro lado, niños de entre 7 y 14 ańos experimentaron, gracias a la ley 10639, un acceso casi total al sistema de educación. Sin embargo, dicha ley no ocupaba un lugar importante en la agenda de educación, el sistema de enseñanza no era eficiente y el incremento del nivel de competencia de estudiantes tuvo como resultado la pérdida de calidad, con la reducción del promedio de calificaciones. Si bien la expansión del sistema de enseñanza y las políticas afirmativas redujeron los niveles de desigualdad, siguen experimentando discriminación racial en las aulas (Paixao, 2010). Vemos que estas acciones no atacaban los problemas de educación de manera integral.

Por otro lado, el mercado de trabajo presentó un incremento de la presencia de la mujer. Sin embargo, esta apertura no fue igual para mujeres prietas y pardas, quienes laboran principalmente en el sector doméstico, de manera informal y, por tanto, sin prestaciones de seguridad social y con bajas remuneraciones. Entre 1995 y 2006 se registraron 3.6 millones de desempleados, la mayoría, prietos, pardos y mujeres. Entre 2000 y 2006 hubo una mejora en el mercado laboral, debido a la aplicación de acciones afirmativas como las políticas de valorización del salario mínimo o de transferencias de ingresos, las cuales ampliaron el poder adquisitivo. Entre los principales beneficiarios se encontraba la población prieta y parda, quienes mejoraron su nivel adquisitivo respecto a los mestizos o los blancos, reduciendo la brecha de ingreso en $15 \%$. Pero, esto no se tradujo en reducción de la pobreza (Paixao, 2010).

Sansone (s/a) analizó el periodo de 1992 a 1999 y Paixao (2010), el de 1995 a 2006. En ambos periodos, los autores presentan proble- 
máticas socioeconómicas como mala distribución del ingreso y de la riqueza, pobreza, reducción de la calidad de la educación pública y desempleo, que asocian a la inequidad racial, pues mencionan que morenos, pardos, prietos y mujeres morenas son lo que más sufren estos problemas. Ésta es una problemática histórica y estructural, ya que las "razas" comienzan a ser una categoría de diferenciación en el marco del Estado Nación. Entonces, posiblemente el problema de fondo no es la diferencia cultural, per se, sino la organización, estructura, y construcción del Estado Nación en términos de una blancura que niega y excluye lo diferente, que ha ido cambiando sistemáticamente sus aparatos y tecnologías de contención y control social, para adaptarse a los nuevos contextos y desafíos sociopolíticos y económicos, que le permitan seguir ejerciendo su hegemonía (Goldberg, 2002; Saldívar, 2014).

Los resultados positivos de las políticas multiculturales en Brasil han sido temporales e insuficientes, pues no han atacado el problema estructural de la pobreza, la mala distribución del ingreso, el racismo y la discriminación. Paixao (2010) y Sansone (s/a) mencionan que es necesario establecer criterios en la selección de los beneficiarios; es decir, ¿quién las necesita?, y que las acciones afirmativas sean acompańadas de herramientas de autogestión; es decir, que sea un verdadero empoderamiento y no soluciones asistenciales temporales. Por su parte, Rangel (2016) menciona que el fracaso de acciones afirmativas en educación y el abandono de estudios por personas que entraron por medio del sistema de cuotas, se puede deber a que no las gestionaron, ejecutaron ni diseñaron "con la finalidad y dimensión del problema que intentan combatir" (traducción libre de Negreiros, citado por Rangel, 2016, p. 32). Es decir, no fueron diseñadas para combatir el problema al que son aplicadas.

\section{Colombia}

El auge de la movilización afrocolombiana fue en la década de los noventa, después de que la Constitución Política de 1991 reconociera a la población afrodescendiente, y su artículo transitorio 55, reglamentado por la ley 70 de 1993, abriera la senda para la titulación colectiva de las tierras del Pacífico. A decir de Antón y Rivera (2010, p. 150), en esta década la movilización afrocolombiana "gozó de una madurez y liderazgo propio que le permitió sobreponerse a 
las fracturas y las contradicciones internas... maduró un discurso alrededor de la etnicidad, la ancestralidad y contra la discriminación". Entre los logros del movimiento se encuentran, por supuesto, el reconocimiento constitucional, la obtención de derechos colectivos a la tierra, espacios de representación en instituciones gubernamentales, políticas y culturales, instituciones creadas específicamente para afrocolombianos, políticas para atender a la población desplazada, inclusión en Planes Nacionales de Desarrollo, y políticas de acción afirmativa en diversos ámbitos (López, 2017).

Agudelo menciona que las interacciones entre el Estado y los actores de la movilización, entre la reforma de la Constitución de 1991 y la formulación de la ley 70 de 1993, fueron intensas. Sin embargo, comenzaron su debacle en 1998. Las complicaciones comenzaron con la "ambigüedad expresada en una especie de 'resistencia' en la aplicación y el desarrollo de dichas políticas o simplemente en su desviación" (Agudelo, 2015, p. 10). Además, se abren coyunturas como el conflicto armado en la zona del pacíico, que tiene como consecuencia el desplazamiento forzado y el debilitamiento en la organización de la movilización. Así, el significado de la titulación colectiva de las tierras se fue desgastando, debido a las pérdidas paulatinas de territorio por los conflictos armados, los espacios en la cámara de representantes eran cuestionados, ya que en algunas ocasiones fueron tomados por personas ajenas a las comunidades negras, y los procesos de consulta, en base al Convenio 169 de la OIT, perdieron legitimidad por fallas en su aplicación.

Antón y Rivera mencionan que existe una situación de racismo, vulnerabilidad y pobreza para los afrocolombianos. Además, los datos de las encuestas de condiciones de vida y de los censos oficiales de los indicadores de etnicidad, calidad de vida y equidad social, muestran que las comunidades afrocolombianas "no tienen garantizados sus más elementales derechos económicos, sociales y culturales y, como consecuencia de ello, sus derechos al desarrollo y a una calidad de vida digna son menoscabados" (Antón y Rivera, 2010, p, 127). En resumen, las fuentes utilizadas mostraron que la población afrocolombiana se encuentra viviendo en peores condiciones 
que la población mestiza. ${ }^{6}$ Respecto a la educación, el Observatorio de Discriminación Racial de la Universidad de los Andes (ODR) y el censo de 2005 identificaron que la población afrocolombiana presenta tasas de analfabetismo más altas, que los niños afrocolombianos acceden en menor porcentaje a la educación básica, media y superior, y que se enfrentan a diversos tipos de discriminación durante su permanencia en el sistema educativo. Por último, también se ha identificado que los afrocolombianos no gozan plenamente del acceso a los servicios de salud y a los servicios públicos (Rodríguez, Alfonso y Cavelier, citados por Antón y Rivera, 2010). En Colombia, de manera similar a Brasil, a pesar de que el movimiento afrodescendiente logró madurar un discurso y un liderazgo que le permitió conquistar diversos derechos, las políticas aplicadas no sortearon problemáticas estructurales como el racismo y la pobreza. Por ende, indicadores sociales como educación y salud siguen mostrando un mal desempeño.

\section{Honduras}

La población afrodescendiente hondureña se autoidentifica y es conocida como "garífuna"; son descendientes de esclavos africanos e indígenas caribes y arahuacos. Han sabido manejar su ascendencia indígena y africana de acuerdo con la coyuntura política, ya que, en el marco del auge de los movimientos indígenas, durante la década de los setenta, abrazaron esa identidad con el objetivo de "lograr reconocimiento en algunos espacios internacionales" (Roy Guevara, líder garífuna, citado por Agudelo, 2011, p. 12). Luego, cuando emergieron las movilizaciones negras, al fin de la década de los ochenta, transformaron sus dinámicas organizativas y reivindicaron sus raíces africanas. Entonces, para este sujeto utilizaré garífuna y afrodescendiente como símil.

Los orígenes o antecedentes del movimiento garífuna se pueden establecer en la primera mitad del siglo XX, con la llegada de las compañías bananeras norteamericanas a las tierras costeras del norte de Honduras. La instalación de las compañías supuso el desarrollo de sindicatos que desarrollaron, en el marco de una dictadura mi-

${ }^{6}$ Los autores no contrastan los datos con la población indígena. 
litar, explotación laboral de parte de las compañías bananeras y de pequeñas fábricas de la región, y de un aumento de prácticas de discriminación racial hacia los trabajadores, un significativo activismo político. (Anderson, citado por Cuisset, 2014). Además, aquellos que se oponían a la dictadura militar, entre 1940 y 1950, se asilaron en Estados Unidos y fueron influidos por el movimiento afroamericano de derechos civiles (Agudelo, 2011). Este activismo es una forma de organización sociopolítica que adoptaron en Honduras, distinta de los movimientos de Brasil y Colombia.

En 1977 nació la OFRANEH, “organización 'madre' y 'matriz' del movimiento a nivel nacional” (Cuisset, 2014, p.92). Retomó las demandas de la etapa sindicalista de los años cincuenta y setenta e incorporó, en el marco de la apertura y auge de las políticas multiculturales y de los movimientos indígenas a mediados de los ochenta, demandas por derechos colectivos de las tierras y derechos culturales, lo cual se complementaba con la denuncia de la situación económica, carencia de servicios básicos de salud, y un sistema de educación y de transporte deficiente (Cuisset, 2014). En 1987, durante el primer seminario con los grupos autóctonos de Honduras, organizado por la Secretaria de Planificación del Gobierno, SECPLAN, los garífunas demandaron la recuperación y titulación de la tierra, aunque se habían plasmado en papel desde 1982, no se habían trasladado a la práctica, el derecho de explotación de los recursos naturales, el reconocimiento y la promoción de los idiomas y las culturas de todas las etnias, y la participación política. Finalmente, los primeros títulos colectivos de la tierra se otorgaron a inicios de la década de los noventa, a la vez que el Estado implementó diversas acciones afirmativas de corte simbólico-cultural, ratificó el Convenio 169 de la OIT, el reconocimiento constitucional de Honduras como un país pluriétnico (Cuisset, 2014), el establecimiento de la "punibilidad de la discriminación... en el código penal hondureño" (Hooker, Dixón, Gómez et al., 2010, p. 287), y elaboró un perfil para el pueblo indígena y el garífuna con el objetivo de identificar su situación socioeconómica.

A pesar de la implementación de estas políticas, el Estado no había cumplido con el mejoramiento de infraestructura, servicios, ni con el otorgamiento de la propiedad colectiva de la tierra. Además, Cuisset (2014) menciona que se vivía un ambiente de represión po- 
licial en el que los líderes eran amenazados o asesinados, y se experimentó un estallido de clientelismo político. ODECO, OFRANEH, y las Organizaciones Negras de Honduras (ONH) organizaron una marcha de protesta y lograron entablar una negociación. El gobierno se comprometió a otorgar títulos de propiedad colectiva de la tierra, así como a la ampliación y saneamiento de las tierras comunitarias. Sin embargo, Cuisset (2014, p. 102) nos dice también que los títulos colectivos de las tierras, "sólo abarcaron el casco urbano", y no el hábitat, como lo estipula el Convenio 169 de la OIT.

En 1995 se creó la Organización Negra Centroamericana (ONECA), en la que Celeo Álvarez, líder de ODECO, "se constituyó rápidamente como figura clave del movimiento negro a nivel regional" (Cuisset, 2014, p. 103). ODECO se posicionó como el órgano de representación del movimiento garífuna. Así, Álvarez comenzó a invitar a los candidatos de las campañas presidenciales a "firmar 'compromisos de campaña' relativos a la titulación de la tierra, apoyo técnico y financiero, servicios públicos, acciones contra el racismo y la discriminación, racial, promoción de la cultural y del turismo comunitario, etc.” (Cuisset, 2014, p.104). Las únicas respuestas que logró fueron la implementación de políticas de acción afirmativa de corte simbólico-cultural, como la declaración del mes de la herencia cultural africana. Por otro lado, aumentaron los megaproyectos turísticos en zonas naturales y las expropiaciones de la tierra. La implementación de estas acciones afirmativas se plasman en el cuadro 5 del tercer apartado.

En comparación con Brasil y Colombia, las tasas de asistencia al nivel básico de educación de los afrodescendientes hondureños son altas. Sin embargo, es necesario tomar en cuenta el contexto local, ya que "el vínculo con la educación está estrechamente relacionado con la incursión de la iglesia en las comunidades afrodescendientes, especialmente la iglesia morava" (Hooker, Dixón, Gómez et al., 2010, p. 313). No obstante, también registran problemas de acceso a la educación. Por otro lado, al igual que en el caso colombiano, los garífuna están enfrentando pérdidas de territorio por los megaproyectos de corte turístico, registran altas tasas de pobreza, son víctimas de prácticas de discriminación racial, las tasas de mortalidad infantil también son elevadas, existen problemas, al igual que en Brasil, de equidad de género, y poca aplicación de políticas de acción afirma- 
tiva en otras variables que no sea la simbólica-cultural. En resumen, ni la fuerte organización y movilización política que presentan las organizaciones, ni sus estrategias contestatarias, que cuestionan y critican el sistema, o las de incorporación al sistema, han logrado que los derechos conquistados, específicamente el de la titulación de la propiedad colectiva de la tierra, sean plenamente aplicados, y la situación socioeconómica tampoco ha logrado ser transformada.

\section{POSICIÓN DE LA MOVILIZACIÓN ETNOPOLÍTICA AFROMEXICANA DE LA COSTA CHICA DE GUERRERO Y OAXACA EN EL MARCO DE LAS LUCHAS AFRODESCENDIENTES DE AMÉRICA LATINA ${ }^{7}$}

Los resultados de la Encuesta Intercensal de 2015 del INEGI mostraron que Guerrero (7.61\%), Oaxaca (5.89\%) y Veracruz (4.07\%), son los estados con mayor porcentaje de personas que se autorreconocen como afrodesendientes. Este artículo se enfoca en Guerrero y Oaxaca, estados vecinos que comparten un área de la zona costera Pacífica conocida como Costa Chica. Ziga (2015) nos dice que no se puede entender la emergencia del afromexicano políticamente organizado si no entendemos a la Costa Chica. Se trata de un espacio territorial, cultural, económico y político, en el que se han insertado, apropiado y relacionado con los demás grupos que lo habitan, y porque es el espacio en el que surgen organizaciones que comenzaron a rescatar la herencia cultural africana y a plantear el reconocimiento constitucional. Las participaciones del resto de los estados han sido esporádicas. Por tanto, la Costa Chica se ha convertido en la región protagonista y en el seno de la movilización.

Cuadro 6. Principales políticas multiculturales y logros de la movilización afromexicana

\begin{tabular}{|r|c|l|}
\hline Políticas multiculturales & Posición & Característica \\
\hline $\begin{array}{r}\text { Reconocimiento de la } \\
\text { diversidad y pluralidad }\end{array}$ & Sí & Sólo derechos culturales para los indígenas. \\
\hline $\begin{array}{r}\text { Variable afrodescendiente y } \\
\text { datos estadísticos }\end{array}$ & Sí, tardía & $\begin{array}{l}\text { Encuesta Intercensal en 2015 es decir, entre la segunda (2010) y } \\
\text { tercera (2020) ronda de censos. }\end{array}$ \\
\hline $\begin{array}{r}\text { Porcentaje de } \\
\text { De acuerdo a la última ronda, los porcentajes se organizan así: } \\
\text { reconocimiento de población } \\
\text { afrodescendiente }\end{array}$ & Baja & $\begin{array}{l}\text { 2. } 10 \% \text { al } 30 \% \\
\text { 3. } 1 \% \text { al } 2 \%: \text { México. } \\
\text { 4. (-) } 1 \%\end{array}$ \\
\hline
\end{tabular}

${ }^{7}$ Para consultar a detalle un estudio de caso de la movilización etnopolítica afromexicana, véase López, 2018. 


\begin{tabular}{|c|c|c|}
\hline Políticas multiculturales & Posición & Característica \\
\hline $\begin{array}{r}\text { Reconocimiento } \\
\text { constitucional }\end{array}$ & No & $\begin{array}{l}\text { De los } 18 \text { países tomados en cuenta, México se encuentra entre } 11 \\
\text { que no han otorgado el reconocimiento constitucional. En febrero } \\
\text { de } 2019 \text { se realizaron Foros de Consulta por el Reconocimiento } \\
\text { constitucional del Pueblo Afromexicano bajo la batuta de los } \\
\text { senadores Susana Harp y Martí Batres. }\end{array}$ \\
\hline $\begin{array}{r}\text { Propiedad colectiva de la } \\
\text { tierra }\end{array}$ & No & $\begin{array}{l}\text { La demanda no es fuerte debido a la creación de tierras ejidales y } \\
\text { comunales por la reforma agraria de inicios del siglo XX (Burguete, } \\
\text { 2003; Lewis, 2012). }\end{array}$ \\
\hline $\begin{array}{r}\text { Legislación contra el racismo } \\
\text { y la discriminación }\end{array}$ & Media & $\begin{array}{l}\text { Los instrumentos jurídicos son de carácter federal y no contienen } \\
\text { especificaciones para la población afromexicana. Por otro } \\
\text { lado, herramientas como conversatorios, seminarios, encuestas } \\
\text { y la guía para la acción pública contra la discriminación y } \\
\text { para la promoción de igualdad e inclusión de la población } \\
\text { afrodescendiente, comenzaron a ser dirigidas a la población } \\
\text { afromexicana a partir de } 2011 \text { desde el nivel federal. Ni Guerrero, } \\
\text { ni Oaxaca tienen leyes, organismos o herramientas específicas } \\
\text { para la lucha y prevención de la discriminación racial. La SAICA- } \\
\text { Guerrero, firmó en } 2015 \text { un convenio con Conapred, pero no } \\
\text { causó impacto. }\end{array}$ \\
\hline Políticas de acción afirmativa & $\begin{array}{l}\text { Media/ } \\
\text { alta }\end{array}$ & $\begin{array}{l}\text { De las ocho variables identificadas y elegidas para esta } \\
\text { investigación, México ha aplicado cinco a nivel estatal y federal. } \\
\text { Guerrero presenta más actividad en cuanto a su aplicación. No } \\
\text { obstante, estas acciones se implementaron durante la gestión de } \\
\text { Martha Sánchez Néstor en la Secretaría de Asuntos Indígenas y } \\
\text { Comunidades Afromexicanas (SAICA) en 2015; por tanto, pudo } \\
\text { haber sido una actividad coyuntural. }\end{array}$ \\
\hline Creación de organizaciones & Tardía & $\begin{array}{l}\text { La primera organización afromexicana se creó en 1997, a finales } \\
\text { del periodo de auge de la creación del resto de organizaciones. } \\
\text { El marco de las organizaciones afromexicanas más activas de la } \\
\text { movilización se terminó de configurar en } 2008 .\end{array}$ \\
\hline $\begin{array}{r}\text { Interacción e interconexión a } \\
\text { nivel regional }\end{array}$ & Baja & $\begin{array}{l}\text { La movilización tiene poca interacción con otras organizaciones } \\
\text { afrolatinoamericanas y sólo dos grupos, Cátedra Itinerante } \\
\text { de Mujeres Afromexicanas y Socpinda, pertenecen a una red } \\
\text { transnacional. }\end{array}$ \\
\hline $\begin{array}{r}\text { Interacción con Organismos } \\
\text { Internacionales }\end{array}$ & Baja & $\begin{array}{l}\text { México interactuó con apenas tres organismos, cerca del último } \\
\text { lugar, que ocupan países que tuvieron de } 2 \text { a } 0 \text { interacciones. }\end{array}$ \\
\hline Políticas Públicas & No & Es necesario que sean reconocidos constitucionalmente. \\
\hline
\end{tabular}

Fuente: cuadro de elaboración propia con datos de López (2017) y trabajo de campo en 2013, 2014 y 2015.

El cuadro 6 es una síntesis del apartado sobre las principales políticas multiculturales aplicadas a poblaciones afrodescendientes en América Latina (ver cuadros 2, 3, 4 y 5), pero se enfoca en identificar los logros que ha experimentado la movilización afromexicana. Se aprecia que su posicionamiento respecto a los derechos conquistados es de los más bajos. ¿Por qué no han logrado conquistar derechos como Brasil, Colombia, Ecuador o Nicaragua? El afromexicano, como sujeto políticamente organizado, se configuró y se integró tarde al marco de las luchas afrodescendientes de América Latina, 
cuando el apogeo de la coyuntura política internacional del reconocimiento de la diferencia y la condena a la discriminación racial estaba pasando. En el ámbito nacional, cuando inició la articulación y organización política con el Primer Encuentro de Pueblos Negros en 1997 (López, 2017, pp. 132-138), la gesta de la movilización tampoco coincidió con alguna ventana de oportunidad política. El auge del zapatismo estaba pasando y, posteriormente, las cumbres de Santiago (2000) y Durban (2001), si bien tuvieron un relativo impacto a nivel nacional en cuanto al tema de racismo y discriminación, no impactó significativamente en lo afromexicanos.

Por otro lado, en el caso de México, la movilización está muy localizada en la Costa Chica de Guerrero y Oaxaca; de manera intermitente se unen e interactúan otros estados como Veracruz o Coahuila. Sin embargo, existe una fragmentación de las organizaciones, que hace que la correlación de fuerzas al interior, la cual es muy importante, sea débil o inexistente y, por tanto, se dificulte el avance. Además, como se mencionó en el apartado Organizaciones y redes: interacción nacional y transnacional, las organizaciones afromexicanas no han desplegado herramientas de movilización significativas.

\section{REFLEXIÓN}

La movilización etnopolítica afromexicana es una pieza que compone el marco de las luchas afrodescendientes en la región latinoamericana, aunque con características y especificidades propias; tienen objetivos en común en cuanto a reivindicaciones y demandas, utilizan herramientas y estrategias similares de movilización política, como la constitución de organizaciones, la participación en redes trasnacionales, la interacción con organismos internacionales, agencias financieras, ONG, entre otros, presentan un perfil socioeconómico y se enfrentan a obstáculos similares.

Los derechos hasta ahora conquistados por las luchas afrodescendientes de América Latina, si bien son parecidos, tienen tiempos, resultados y efectos sociales diferentes. Algunos son: incorporación de la variable afrodescendiente en las rondas censales y aumento de personas que se reconocen como afrodescendientes, reconocimiento 
constitucional, bien cultural, bien político, derechos a la propiedad colectiva de la tierra, formulación de legislación y herramientas para luchar contra el racismo y la discriminación, y la aplicación de políticas de acción afirmativa en áreas de incidencia social. De manera general, es posible afirmar que existe un avance en la conquista de derechos a través de la aplicación de políticas multiculturales. Sin embargo, éstas no han sido diseñadas de acuerdo con las necesidades, tampoco ejecutadas efectivamente y los resultados que, en algunos casos, han sido positivos, han sido de breve duración.

Los casos de Brasil, Colombia, y Honduras ejemplifican esta afirmación. Los tres muestran problemáticas socioeconómicas y demandas similares. Por un lado, es interesante ver cómo Brasil y Colombia, con una población numéricamente considerable, no han logrado que las políticas multiculturales que han alcanzado impacten y redunden en un cambio positivo y estructural en su población afrodescendiente. Por otro lado, Honduras, con una población numéricamente menor a Brasil, Colombia y México, y con fuertes procesos organizativos, sobre todo sindicales y políticos, no han logrado aplicar políticas multiculturales, en específico la demanda de la propiedad colectiva de la tierra, como en Brasil y Colombia, y las políticas conquistadas son principalmente acciones afirmativas de corte simbólico-cultural o de etnoturismo, que no han devenido en una transformación social profunda.

Esta breve comparación muestra que, ni los países más exitosos en la aplicación de políticas multiculturales para afrodescendientes, como Brasil y Colombia, han logrado una verdadera transformación estructural y, por ende, un mejoramiento social de sus poblaciones afrodescendientes. Aún hay obstáculos en el ejercicio de sus derechos, persiste la discriminación racial, una precaria situación socioeconómica, y si experimentaron resultados positivos, fueron temporales, e incluso han retrocedido en algunas variables. Por tanto, aunque la situación de invisibilidad quedó atrás, existe un debilitamiento y desgaste de las luchas afrodescendientes por la ausencia de resultados positivos, retroceso de los logros y ausencia de nuevos liderazgos.

Entonces, el otorgamiento de derechos y políticas multiculturales no necesariamente conduce a una verdadera transformación en 
las dinámicas y estructuras políticas, económicas y sociales. Además, no han sido acompañados o complementados con una efectiva redistribución de la riqueza, como Fraser (2001) ha sugerido. Han sido, más bien, parches asistencialistas a corto plazo, que no toman en cuenta problemas estructurales sociales, políticos y económicos, contextos específicos, así como características y particularidades locales. En adición, vemos que en el contexto de un mundo globalizado, con un régimen económico neoliberal, a pesar de la aparente debilidad del Estado por la aparición de nuevos actores internacionales y el desdibujamiento de las fronteras, las luchas sociales siguen siendo contenidas y limitadas, ahora por la intervención de actores no estatales, con los que también se tiene que entablar un diálogo y comenzar a interactuar. ¿Qué mecanismos podrían lograr una incidencia real? Ésta es una cuestión compleja y difícil, pero es necesario descifrar si los afrodescendientes desean continuar su camino dentro del marco multicultural.

Si los resultados que han experimentado los movimientos afrodescendientes que han registrado más avance no es tan favorable; ¿cuál es la situación de la movilización afromexicana? Vemos que se posiciona como una de las luchas afrodescendientes que emergió tardíamente; sus interacciones con organismos internacionales, organizaciones y redes transnacionales son débiles y presenta avances menores, respecto al resto de luchas afrodescendientes en América Latina. Entonces, la movilización etnopolítica afromexicana tiene la oportunidad de mirar y reflexionar los casos de otras movilizaciones para cambiar estrategias, reforzar alianzas, identificar lo que no ha funcionado y las necesidades específicas de su pueblo, ya que las políticas hasta ahora implementadas, no han sido diseñadas para satisfacer sus necesidades específicas, ni para cambiar la estructura base de los problemas de esta población, como lo es la pobreza, la cual resulta en bajos niveles de educación que, a la vez, repercute en los ingresos. Pero, sobre todo, es necesario desmadejar el nudo problemático al interior de las organizaciones que forman la movilización. 


\section{REFERENCIAS BIBLIOGRÁFICAS}

Agudelo, C. (2010a). Génesis de Redes Transnacionales. Movimientos Afrolatinoamericanos en América Central. En O. Hoffmann, (Coord.), Politica e Identidad. Afrodescendientes en México y América Central (pp. 65-92). México: CONACULTA, INAH, CEMCA, UNAM, CIALC, IRD.

Agudelo, C. (2010b). Movilizaciones afrodescendientes en América Latina. Una visión panorámica de algunas experiencias contra la exclusión y por el derecho a la identidad. Revista Colombia Internacional, 71, 109-126.

Agudelo, C. (2011). Los garífuna, múltiples identidades de un pueblo afrodescendiente en América Central. REMI, Revue Européenne des Migrations Internacionales, 27(1), 47-70.

Agudelo, C. (2015). Las encrucijadas del reconocimiento multicultural. Los afrodescendientes en América Latina y el Caribe. En S. Valero y A. Campos (Eds.), Identidades politicas en tiempos de Afrodescendencia: Auto-identificación, Ancestralidad, Visibilidad y Derechos Humanos (pp. 1-34). Buenos Aires: Ediciones corregidor.

Agudelo, C., y Recondo, D. (2007). Políticas del multiculturalismo en América Latina. Del Pacífico mexicano al Pacífico colombiano. En M.T. Rodríguez y O. Hoffmann, Reseña del tercer coloquio Idymov. Construir y vivir la diferencia. Los actores de la multiculturalidad en Colombia y México (pp. 1-13). Xalapa, México: CEMCA-IRD-CIESAS-ICANH.

Aguilar, L. (1992). La hechura de las políticas públicas. México: Miguel Ángel Porrúa.

Antón, J., y Del Popolo, F. (2008). Visibilidad estadistica de la población afrodescendiente de América Latina: aspectos conceptuales y metodológicos. Santiago de Chile: CEPAL.

Antón, J., y Rivera, M. (2010). Implementación de los pactos y convenios internacionales relacionados con los derechos civiles, culturales, económicos, políticos y sociales de la población afrodescendiente de Colombia, Ecuador, Perú y Venezuela. En S. García (Ed.), Derechos de la población afrodescendiente de América Latina: Desafíos para su implementación (pp. 90-170). Panamá: PNUD.

Appiah, K. (1994). Identity Against Culture. Understandings of Multiculturalism. Berkeley: University of California. 
Arias, R. (marzo de 2015). Desarrollo y Pueblos Afrodescendientes. En Panel de discusión sobre el Marco Legal, Derecho al Desarrollo y Pueblos Afrodescendientes. Ponencia presentada en la 16a sesión del Grupo de Trabajo de Expertos sobre Afrodescendientes, Ginebra, Suiza.

Becerra, M. J., Buffa, D., Celton, D., Peláez, E., Molinatti, F., Vagni, J.J., y Schaller, P. (2010). Implementación de los pactos y convenios internacionales relacionados con los derechos civiles, culturales, económicos, políticos y sociales de la población afrodescendiente de Argentina, Bolivia, Chile, Paraguay y Uruguay. En S. García, (Ed.), Derechos de la población afrodescendiente de América Latina: Desafios para su implementación (pp. 14-87). Panamá: PNUD.

Buffa, D., y Becerra, M. J. (2012). La población afrodescendiente en América Latina y el Caribe. Estado, sociedad civil y Derechos Humanos. En M. J. Becerra, D. Buffa, H. Noufouri y M. Ayala, (Comps.), Las poblaciones afrodescendientes de América Latina y el Caribe. Pasado, presente y perspectivas desde el siglo XXI (pp. 333-353). Córdoba, Argentina: Universidad Nacional de Córdoba.

Burguete, C., y Mayor, A. (2003). The facto autonomous process: new Jurisdictions and parallel governments in rebellion. En J. Rus, R. Hernández y M. Kanham (Eds.), Mayan Utopia: the indigenous peoples of Chiapas and the Zapatista rebellion (pp. 191-218). Estados Unidos: Rowman \& Littlefield Publishers.

Canto, M. (2002). Introducción a la Políticas Públicas. En M. Canto y O. Castro (Coords.), Participación Ciudadana y Politicas Públicas (pp. 59-77). Mexico: MCD.

CEPAL. (2015). Panorama social de América Latina. Santiago de Chile: CEPAL-Naciones Unidas.

CIDH. (2011). La Situación de las personas Afrodescendientes en las Américas. Recuperado de http://bibliotecadigital.indh.cl/handle/123456789/197

CONAPRED. (2011a). Documento Informativo sobre Discriminación Racial en México. México: CONAPRED.

CONAPRED. (2011b). Guía para la acción pública contra la discriminación y para la promoción de igualdad e inclusión de la población afrodescendiente en México. Recuperado de http://www.conapred. org.mx/userfiles/files/GAP AFRO_2011_INACCSS.pdf 
CONAPRED. (21 de agosto de 2015). Realiza Conapred, INAH, y el Movimiento Nacional por la Diversidad Cultural en México (Mndcux) el Encuentro Nacional pro inclusión de la población Afromexicana. [Boletín de prensa 078/2015]. Recuperado de http://www. conapred.org. $\mathrm{mx} /$ index.php? contenido=boletin\&id=815\&id_opcio $\mathrm{n}=103 \& \mathrm{op}=213$

COPRED. (2016). Conversatorio: Racismo y Discriminación en la CDMX. Recuperado de http://copred.cdmx.gob.mx/comunicacionsocial-y-prensa/c/convocatorias-2016/conversatorio-racismo-y-discriminacion-en-la-cdmx/

Constitución Política del Estado Plurinacional de Bolivia [Const.]. (07 de febrero de 2009) [Reformada] Recuperado de http://www.ftierra.org/ index.php/generales/14-constitucion-politica-del-estado

Constitución de la República Bolivariana de Venezuela. [Const.]. (15 de diciembre de 1999). [Enmendada] Última modificación 14 de octubre de 2011. Recuperado de http://www.mpptaa.gob.ve/publicaciones/leyes-y-reglamentos/constitucion-de la-republica-bolivariana-devenezuela

Constitución de la República de Chile [Const.]. (17 de septiembre de 2005). [Reformada] Última versión 4 de mayo de 2017. Recuperado de https://www.leychile.cl/Navegar?idNorma $=242302 \& i d$ Version $=20$ 17-05-04

Constitución Política de la República de Costa Rica [Const.]. (9 de noviembre de 1949). [Reformada] Última versión 24 de agosto de 2015. Recuperado de http://www.pgrweb.go.cr/scij/Busqueda/Normativa/ Normas/nrm_texto_compl eto.aspx?nValor $1=1 \&$ nValor $2=871$

Constitución Política de la República de Ecuador. [Const.]. (20 de octubre de 2008). [Reformada] Última modificación 13 de julio 2011. Recuperado de http://www.oas.org/juridico/pdfs/mesicic4_ecu_const.PDF

Constitución Política de la República de El Salvador. [Const.]. (15 de diciembre de 1983). [Reformada] Última modificación 12 de junio de 2014. Recuperado de http://www.asamblea.gob.sv/eparlamento/ indice-legislativo/buscador-de-documentos-legislativos/constitucionde-la-republica

Constitución Política de la República de Guatemala. [Const.]. (31 de mayo de 1985). [Reformada] Última modificación 17 de noviembre de 1993. 
Constitución Política de la República Honduras. [Const.]. (20 de enero de 1982). [Reformada] Última modificación en 2014. Recuperado de http://www.conaprev.gob.hn/index.php/biblioteca-virtual-pdf/ send/19-leyes de-interes/992-constitucion-de-la-republica-de-honduras-actualizada-2014

Constitución de la República Oriental del Uruguay. [Const.]. (15 de febrero 1967). [Reformada] Última modificación 31 de octubre de 2004. Recuperado de https://parlamento.gub.uy/documentosyleyes/ constitucion

Constitución Política de la República de Panamá. [Const.]. (11 de octubre de 1972). [Reformada] Última modificación 15 de noviembre de 2004. Recuperado de http://www.ilo.org/dyn/travail/docs/2083/ CONSTITUTION.pdf

Constitución Política de los Estados Unidos Mexicanos. CPEUM. [Const.]. (5 de febrero de 1917). [Reformada] Última modificación 24 de febrero de 2017). Recuperado de http://www.diputados.gob. mx/LeyesBiblio/pdf/1_240217.pdf

Constitución Política de Nicaragua. [Const.]. (9 de enero de 1987). [Reformada] Última modificación 18 de febrero de 2014. Recuperado de http://aceproject.org/ero en/regions/americas/NI/constitucion/ constitucion-politica-de-nicaragua-con reformas-a/view

Cuisset, O. (2014). Del campo a la ciudad y vice-versa: elementos para la historia del movimiento garífuna en Honduras. Revista de Estudos \& Pesquisas sobre as AMERICAS, 8(1), 89-111. Recuperado de: http:// periodicos.unb.br/index.php/repam/article/download/11450/8116

Departamento Administrativo Nacional de Estadística de Colombia (DANE). (2005). Censo General 2005. Recuperado de https://www. dane.gov.co/index.php/estadisticas-por-tema/demografia-y-poblacion/censo-general-2005-1

De Ferranti, D., Perry, G., Ferreira, F., Walton, M., Coady, D., Cunningham, W., Gasparini, L., Jacobsen, J., Matsuda, Y., Robinson, J., Sokoloff, K., y Wodon, Q. (2004). Desigualad en América Latina y el Caribe: ¿Romper con la historia? Washington: Banco Mundial/Alfaomega.

Del Popolo, F. (2013). Los censos de 2010 en América Latina: balance y principales lecciones aprendidas. Santiago de Chile: CELADE-CEA/ CEPAL-UNFPA. 
Díaz. D. (2015). El Decenio y la integración de los pueblos. América Latina en Movimiento. El decenio Afrodescendiente, 39(2), 9-11.

Dirección General de Estadística y Censos (DIGESTYC) de El Salvador. (2008). VI Censo de Población y V de Vivienda 2007. Recuperado de http://www.censos.gob.sv/cpv/descargas/CPV_Resultados.pdf

Embajada de la República Bolivariana de Venezuela en Estados Unidos. (2012). Recuperado de http://eeuu.embajada.gob.ve/

Excélsior. (27 de septiembre de 2014). Van contra la discriminación; lanza Conapred campaña Sin Tags. Recuperado de http://www.excelsior. com.mx/nacional/2014/09/27/983992

EZLN. (1996). Pronunciamiento conjunto que el gobierno federal y el EZLN enviarán a las instancias de debate y decisión nacional. En Acuerdos de San Andrés, apartado 3, 6 de febrero de 1996.

Flores, J. (2006). Afrodescendientes en México; Reconocimiento y Propuestas antidiscriminación. Dirección General Adjunta de Estudios, Legislación y Políticas Públicas. Documento de Trabajo N. E-19-2006. México: CONAPRED.

Fraser, N. (2001). Recognition without ethics. Theory, Culture and Society, $18(2), 21-42$.

García, S. (2010). Presentación y agradecimientos. En S. García (Ed.), Derechos de la población afrodescendiente de América Latina: Desafios para su implementación (pp. 10-11). Panamá: PNUD.

García, S. (2016). La internacionalización del multiculturalismo liberal como estructura de posibilidad para su circulación en América Latina. Revista De Estudios Sociológicos, 57,12-24. doi: http://dx.doi. org/10.7440/res57.2016.01

Goldberg, D. (2002). The Racial State. Estados Unidos y Reino Unido: Blackwell.

Hale, C. (2002). Does Multiculturalism Menace? Governance, Cultural Rights and the Politics of Identity in Guatemala. Journal of Latin American Studies, 34, 485-52.

Hale, C. (2005). Neoliberal Multiculturalism: The Remaking of Cultural Rights and Racial Dominance in Central America. POLAR: Political and Legal Anthropology Review, 28(I), 10-28.

Hoffmann, O., y Lara, G. (2012). Reivindicación afromexicana: formas de organización de la movilización negra en México. En D. Buffa, M. Becerra, N. Hamurabi y M. Ayala (Comps.), Las poblaciones afrodes- 
cendientes de América Latina y el Caribe. Pasado, presente y perspectivas desde el siglo XXI (pp. 25-46). Argentina: Universidad Nacional Tres de Febrero.

Hooker, A., Dixon, B., Gómez, N., Rossman, T., y Fonseca, R. (2010). Implementación de los pactos y los convenios internacionales relacionados con los derechos civiles, culturales, económicos, políticos y sociales de la población afrodescendiente de América Central y México. En S. García (Dir.), Derechos de la población afrodescendiente de América Latina: Desafios para su implementación (pp. 264-366). Panamá: PNUD.

Hooker, J. (2005). Indigenous Inclusion/Black Exclusion: Race, Ethnicity and Multicultural Citizenship in Latin America. Journal of Latin American Studies, 37(2), 285310.

Hooker, J. (2009). Race and the Politics of Solidarity. Nueva York: Oxford University Press.

Hooker, J. (2010). Las luchas por los derechos colectivos de los afrodescendientes en América Latina. En O. Hoffmann (Coord.), Política e identidad: Afrodescendientes en México y América Central (pp. 33-64). México: INAH/UNAM/CEMCA/IRD.

Hooker, J. (2011). Indigenous Rights in Latin America. How to Classify Afro-descendants? En A. Eisenberng y W. Kymlicka (Eds.), Identity Politics in the Public Realm. Bringing Institutions Back In (pp. 104136). Vancouver, Canadá: UBC Press.

Hopenhayn, M., Bello, A., y Miranda, F. (2006). Los pueblos indígenas y afrodescendientes ante el nuevo milenio. Serie políticas sociales. 118. Santiago de Chile: CEPAL.

Instituto Brasileiro de Geografía e Estadística (IBGE). (2010). Censo Demográfico 2010. Recuperado de http://www.ibge.gov.br/home/estatistica/populacao/censo2010/default.shtm

Instituto Nacional de Estadística de Guatemala (INE-G). (2002). Censos Nacionales XI de Población y VI de Habitación. Recuperado de https:/www.ine.gob.gt/sistema/uploads/2014/02/20/jZqeGe1H9WdUDngYXkWt3GIhUUQCukcg.pdf

Instituto Nacional de Estadística de Honduras (INEH-H). (2001). Tomo del censo de población y vivienda 2001 Grupos poblacionales. Recuperado de http://www.ine.gob.hn/index.php/component/content/ article?id $=81$ 
Instituto Nacional de Estadística de la República Bolivariana de Venezuela (INE-V). (2011). Censo de Población y Vivienda 2011. Recuperado de http://www.ine.gob.ve/index.php?option=com content \&view $=$ category\&id=9 5\&Itemid $=26 \#$

Instituto Nacional de Estadística de Uruguay. (INE-U). (2011). Encuesta Continua de Hogares. Recuperado de http://ine.gub.uy/encuestacontinua-de-hogares 1

Instituto Nacional de Estadística e Informática de Perú. (2010). Encuesta Nacional de Hogares sobre Condiciones de Vida y Pobreza 2010. (ENAHO). Recuperado de http://webinei.inei.gob.pe/anda_inei/index.php/catalog/197

Instituto Nacional de Estadística y Censos (INEC-C) de Costa Rica. (2011). X Censo Nacional de Población y VI de Vivienda 2011. Recuperado de https://www.cipacdh.org/pdf/Resultados_Generales_Censo_2011.pdf

Instituto Nacional de Estadística y Censos de Ecuador (INEC-E). (2010). VII Censo de Población y VI de Vivienda 2010. Recuperado de http:// anda.inec.gob.ec/anda/index.php/catalog/270

Instituto Nacional de Estadísticas y Censos de Nicaragua (INEC-N). (2005). VIII Censo de Población y VI de Vivienda, 2005. Recuperado de http://www.nide.gob.ni/censos2005/censo2005.htm

INEGI. (2015). Encuesta Intercensal 2015. Estimadores de la población total y su distribución porcentual según autoadscripción afrodescendiente por entidad federativa, sexo y grandes grupos de edad. México: INEGI.

Kymlicka, W. (1995). Multicultural Citizenship: A Liberal Theory of Minority Rights. Oxford: Clarendon Press.

Kymlicka, W. (2007). Multicultural Odysseys: Navigating the new International Politics of Diversity. Oxford: Oxford University Press.

Lao, A. (2009). Cartografías del campo político afrodescendiente en América Latina. Universitas Humanistica, 68(68), 207-245.

Lao, A. (2015). Movimientos sociales latinoamericanos. América Latina en Movimiento. El decenio Afrodescendiente, 39(2), 5-8.

Lara, G. (2014). Negro-Afromexicanos: Formaciones de alteridad y reconocimiento étnico. En Revista de estudos \& pesquisas sobre as Américas. Afrodescendentes na América Latina y Caribe: novos caminos, novas perspectivas em um contexto global multicultural. Dossie especial, 8(1), 149-175. 
Le Bot, Y. (2009). La Gran Revuelta Indígena. Océano: México.

Lechini, G. (2008). Los estudios sobre África y Afroamérica en América Latina. El Estado del Arte. En G. Lechini (Comp.), D. Buffa, y M. Becerra (Eds.), Los estudios Afroamericanos y Africanos en América Latina. Herencia, Presencia y Visiones del otro (pp. 11-34). Argentina: CLACSO.

Lehmann, D. (Ed.) (2016). The Crisis of Multiculturalism in Latin America. Estados Unidos: Palgrave Macmillan.

Levy, J. (1997). Classifying cultural rights. En I. Shapiro y W. Kymlicka (Eds.), Ethnicity and Group Rights (pp. 22-66). Estados Unidos: New York University Press.

Lewis, L. (2012). Chocolate and Corn Flour. History, Race, and Place in the Making of "Black" Mexico. Estados Unidos: Duke University Press.

López, A. (2017). Afrodescendientes en América Latina. Estudio de caso de la movilización etnopolitica afromexicana de la Costa Chica de Guerrero y Oaxaca, México (1997-2016) (tesis de doctorado). Universidad Autónoma de Madrid, España.

López, A. (2018). La movilización etnopolítica afromexicana de la Costa Chica de Guerrero y Oaxaca: logros, limitaciones y desafíos. Revista Perfiles Latinoamericanos, 26(52), 1-33.

Muteba, J., y Dougé-Prosper, M. (2014). Los afrodescendientes y el giro hacia el multiculturalismo en las "nuevas" Constituciones y otras legislaciones especiales latinoamericanas: particularidades de la región andina. Revista de estudos \& pesquisas sobre as Américas. Afrodescendentes na América Latina e Caribe: novos caminos, novas perspectivas em um contexto global multicultural. 8(1), 220237.

Paixao, M. (2010). Implementación de los pactos y los convenios internacionales con los derechos civiles, culturales, económicos, políticos y sociales de la población afrodescendiente de Brasil: un abordaje basado en los indicadores sociales recientes. En S. García (Dir.), Derechos de la población afrodescendiente de América Latina: Desafios para su implementación (pp. 174 263). Panamá: PNUD.

PNUD. (2012). Visibilidad estadística. Datos sobre población afrodescendiente en censos y encuestas de hogares de América Latina. Panamá: PNUD.

PNUD. (2013). Situación socioeconómica de la población afrodescendiente de Costa Rica. Según datos del X Censo Nacional de Población y VI de vivienda 2011. Panamá: PNUD. 
PNUD. (2016). Informe Regional sobre Desarrollo Humano para América Latina y el Caribe Progreso multidimensional: bienestar más allá del ingreso. Nueva York: PNUD.

Psacharopoulos, G., y Patrinos, H. (1994). Los pueblos indígenas y la pobreza en América Latina. Un análisis empírico. Estudios sociodemográficos en pueblos indigenas. Santiago de Chile: CELADE-CEPAL.

Rangel, M. (2009). Una panorámica de las articulaciones y organizaciones de los afrodescendientes en América Latina y el Caribe. En J. Antón, A. Bello, F. Del Popolo, M. Paixao y M. Rangel. Afrodescendientes en América Latina y el Caribe: del reconocimiento estadístico a la realización de derechos (pp. 87 103). Santiago de Chile: CEPAL-Naciones Unidas.

Rangel, M. (2016). Políticas públicas para afrodescendientes: marco institucional en el Brasil, Colombia, el Ecuador y el Perú. Santiago de Chile: CEPAL-Naciones Unidas.

Rodríguez, L. y Antón, J. (2014). Situación de la población afro-descendiente e indigena en América Latina. Puntos de reflexión para el debate sobre Cairo +20: Brasil: ALAP. Recuperado de http://www.alapop.org/ alap/Serie-E Investigaciones/N4/FINAL_Alap2015_Serie_eInvestigaciones_14012016.pdf

Saldívar, E. (2014). It's not Race It's Culture: Untangling Racial Politics in Mexico. Latin American and Caribbean Ethnic Studies, 9(1), 89-108. Recuperado de http://www.tandfonline.com/doi/abs/10.1080/17442 222.2013.874644

Sansone, L. (s/a). Anti-Racism in Brazil. Nacla. Reporting on the Americas since 1967. Recuperado de https://nacla.org/article/anti-racsm-brazil

SEGIB-PNUD. (2009). Actualidad Afrodescendiente en Iberoamérica. Estudio sobre organizaciones civiles y politicas de acción afirmativa. Madrid: SEGIB.

SEGIB. (2016). Organizaciones de la Población Afrodescendiente de América Latina 2016. Madrid: SEGIB.

Sieder, R. (2002). Introduction. En R. Sieder (Ed.), Multiculturalism in Latin America (pp. 1-23). New York: Palgrave Macmillan.

Wieviorka, M. (2014). The End of Multiculturalism. Recuperado de http:// wieviorka.hypotheses.org/321

Van Cott, D. (2000a). The friendly liquidation of the past: The politics of diversity in Latin America. Pittsburg: University of Pittsburg Press.

Van Cott, D. (2000b). Latin America: Constitutional Reform and Ethnic Rights. Parliamentary Affairs, 53(1), 41-54. 
Van Cott. D. (2001). Explaining Ethnic Autonomy Regimes in Latin America. Studies in Comparative International Development, 35(4), 3058.

Ziga, F. (2015). Historizar la región: Movimiento social y reconocimiento de comunidades negras en Oaxaca. Ponencia presentada en el Coloquio Internacional Afroamérica. UNAM, México. 